\title{
A multidimensional high-resolution assessment approach to boost decentralised energy investments in Sub-Saharan Africa
}

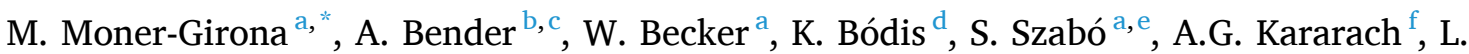 \\ D. Anadon ${ }^{b}$
}

${ }^{\text {a }}$ European Commission, Joint Research Centre (JRC), Ispra, Italy

${ }^{\mathrm{b}}$ University of Cambridge, Centre for Environment, Energy and Natural Resource Governance, Cambridge, United Kingdom

${ }^{\mathrm{c}}$ Victoria University of Wellington, Geography, Environment and Earth Sciences, New Zealand

${ }^{\mathrm{d}}$ Institute of Advanced Studies (iASK), Köszeg, Hungary

e European Institute of Innovation and Technology, Budapest, Hungary

${ }^{\mathrm{f}}$ African Development Bank Group, South Africa

\section{A R T I C L E I N F O}

\section{Keywords:}

Africa

Photovoltaic (PV)

Energy access

Mini-grid

Multidimensional approach

Energy development policy

Energy investments

Spatial analysis

Rural electrification

Composite indicators

\begin{abstract}
A B S T R A C T
There are over 650 million people in Africa who have no access to electricity; this is in sharp contrast to the continent's vast untapped renewable energy potential and due largely to the historical lack of investments in energy infrastructure. New investments in decentralised power generation within Sub-Saharan Africa play a progressively important role in increasing energy access and addressing the continent's electricity supply shortages. Tracking the performance of Sub-Saharan African countries along various socio-political and economic axes can spur the mobilisation of private, public and international sectors in investing in decentralised energy technologies. An increasing amount of high-resolution global spatial data are available, and used for various assessments. However, key multidimensional indicators are mainly still provided only at the national level. To this end, we present a comprehensive and consistent analysis of the attractiveness for decentralised photovoltaic technologies at an unprecedented level of detail using both high-resolution spatial data and national reports. We develop and build a new composite indicator that considers the interplay between social, political, environmental and financial factors at a granular regional level for Sub-Saharan Africa and embeds within it the importance of the local production costs at high-spatial resolution.
\end{abstract}

\section{Introduction}

Increasing energy provision is of paramount importance in SubSaharan Africa (SSA) where currently less than $45 \%$ of the population has access to electricity [1]. The region's installed power generation capacity in 2018 was only $122 \mathrm{GW}$ [2], which is the lowest per capita of any region in the world (equivalent to one-fourth of the consumption in India). The problem is only getting worse: while in SSA population growth is $3 \%$ per year, installed power capacity is growing at only $0.1 \%$ annually (in contrast with $2 \%$ average in emerging economies) [2]. According to the World Bank [3,4] the annual investments needed to close the existing energy access gap by increasing energy infrastructure in Africa is around 45 billion EUR (with a present total accumulated investment of 9 billion EUR).

The requirement for increasing electrification within SSA, is situated within the challenging local context of rising fossil fuel costs and poor grid infrastructure, and the global context of climate change caused by greenhouse gas emissions (GHG) [5]. Against this backdrop, renewable energy technologies (RETs) represent a sustainable option for the strategic deployment of energy technologies in SSA that can improve both energy access and mitigate climate change, whilst balancing these ambitions with important development goals [6-8]. Of the currently available and economically viable RETs, solar energy has by far the largest resource potential in Africa, with high-quality solar resources available everywhere except in the equatorial rainforest areas [9]. Currently, solar photovoltaic (PV) already represents a viable economic and environmentally-friendly alternative to existing grid electricity derived from fossil fuels, or off-grid diesel generators within SSA under certain conditions [10]- particularly in countries with a high retail price of electricity [11-13]. The case for focusing specifically on decentralised PV is made by the poor transmission, distribution [14] and road

\footnotetext{
* Corresponding author.

E-mail address: magda.moner@ec.europa.eu (M. Moner-Girona).
} 


\section{List of abbreviations including units and nomenclature}

BOS Balance-of-system

COIN European Commission's Competence Centre on Composite Indicators and Scoreboards

EODB Ease of Doing Busines

GDP Gross Domestic Product

GHSL Global Human Settlement Layer

HH Household

IMF International Monetary Fund

JRC Joint Research Centre

LCOE Levelised cost of electricity

MICE Multiple Imputation via Chained Equations
MissForest Random Forest Algorithm

NPV Net present value

OECD Organisation for Economic Co-operation and Development

PV Photovoltaic

RETs Renewable energy technologies

SDGs Sustainable Development Goals

PCA Principal Component assessments

PV-DEI PV-Decentralised Energy Investment

SHS Solar Home Systems

SSA Sub-Saharan Africa

UNDP United Nations Development Programme

WEF World Economic Forum infrastructure [15] present particularly in rural areas in many of the SSA countries. The lack of suitable infrastructure impedes traditional grid expansion, which is significant because $59 \%$ of the population live SSA live in rural areas [16]. The ability of decentralised solar PV systems to reduce the need for transmission and distribution infrastructure development means that these systems can be deployed rapidly, with immediate economic and social benefits from increased rural energy access [17].

Up to now, most electrification master plans have focused on centralised options [18]. However, new investments in decentralised power generation within Sub-Saharan Africa play a progressively important role in bringing electricity access to rural communities and providing new opportunities for productive activities and employment. In this paper, we show that there has been a very uneven distribution of decentralized solar PV investments (stand-alone systems and mini-grids) by region and country in SSA. Furthermore, these investments do not seem to align with the amount of solar resources present within a particular country. Why have some countries been more successful than others in attracting decentralised technology investments? The reasons for the lack of investments in solar energy technologies in SSA are likely to be diverse; often the financial infrastructures within countries are embryonic, land tenure agreements may be opaque and the political attitude towards RETs can appear uncertain [19]. Research suggests that some characteristics that are detrimental to decentralized solar PV investment may be present in only one SSA country, but are often generalised to the SSA region as a whole. Consequently, viable investments in solar-PV are being missed [20-24]. This paper investigates the salient environmental/technical, social, fiscal and political barriers and opportunities for investment in decentralised solar PV, differentiated between SSA countries, and presents the data collected in the format of a composite indicator which may be used to direct future investment.

A multidimensional framework to assess the country attractiveness for decentralised energy investment.

Composite indicators are widely used in policy analysis and public communication, providing clear comparisons of countries or regions across a range of complex situations and covering a breadth of topics [25-31]. However, no composite indicator yet exists that directly addresses investments in sustainable energy development and rural electricity access. The need for such an indicator is evidenced by the present heterogeneity in RET investments in SSA, which is dependent not on solar resource potential by myriad other factors, included the costs of production of electricity within a country, the political attitude to RETs, and social factors [32] such as education on the use solar PV technologies within a country. The index presented in this paper integrates a wide range of indices pertaining to the environmental/technical, social, political and fiscal factors that impact investment in decentralised solar $\mathrm{PV}$, into a compact indicator that can serve as a measure to direct funding.

The index focuses on decentralised options, specifically solar PV stand-alone systems and mini-grids. Calculated at the national-level, and covering 38 countries in SSA, it takes into account the multidimensional nature of sustainable energy access by systematically bringing together factors that affect decentralised energy investment [33] (Fig. 1). It includes both national level data, as well as high-resolution satellite data. For specific indicators high-resolution satellite data has been aggregated to create a national level score for use within the composite indicator (named in colour). This satellite data can be accessed within the decision support tool and used to assess energy needs at a higher spatial resolution. For example, identifying unelectrified rural areas at a $1 \mathrm{~km}^{2}$ resolution (Fig. 3). Find more detailed description of the indicators in Table SI. 1 how they were calculated in Fig. 2 and S.I. and where the raw data came from in Table 1 and Table SI.1.

\section{Material and methods}

Given the complex and multi-faceted nature of sustainable energy access [34], the tool is expected to be valuable for researchers, investors, non-for profit organisation and policy makers, to analyse the current suitability of countries when it comes to their attractiveness for investment in decentralised electricity generation.

Each of the four main dimensions (pillars) has been carefully constructed to align with the overall PV Decentralised Energy Investments (PV-DEI) index. High scores in the environmental/technical dimension imply that environmental or technical conditions are favourable to PV mini-grids implementation: favourable resource conditions, sparse existing grid infrastructure, and a high potential to reduce $\mathrm{CO}_{2}$ emissions compared to diesel generators. ${ }^{1}$ High scores in the social dimension imply that the impacts of investing in PV mini-grids are likely to significantly improve various social outcomes. Therefore, indirectly, when current social conditions in the country are lower, the "attractiveness" for the different stakeholders is higher because the impact of bringing electricity can cause more positive social impacts. Finally, the financial and political dimensions score highly when the respective financial and political situations in a country are stable. For example, when control of corruption or electricity regulation is effectively enforced, these contribute to a higher ranking for the political dimension (Table I, Table SI I).

Data normalisation (to ensure comparability between indicators that existed naturally at different scales and ranges, and measured in disparate units), outlier treatment (Winsorization was used to reduce the effect of possibly spurious outliers), imputation of missing data (implementation of a random forest algorithm method), and weighting and aggregation of the 52 indicators (through expert consultations [35] and principal component analyses conducted at multiple levels of the

\footnotetext{
${ }^{1}$ Diesel generators are currently the most accessible and popular alternative to decentralised RETs, and thus represent the point of comparison in this study.
} 

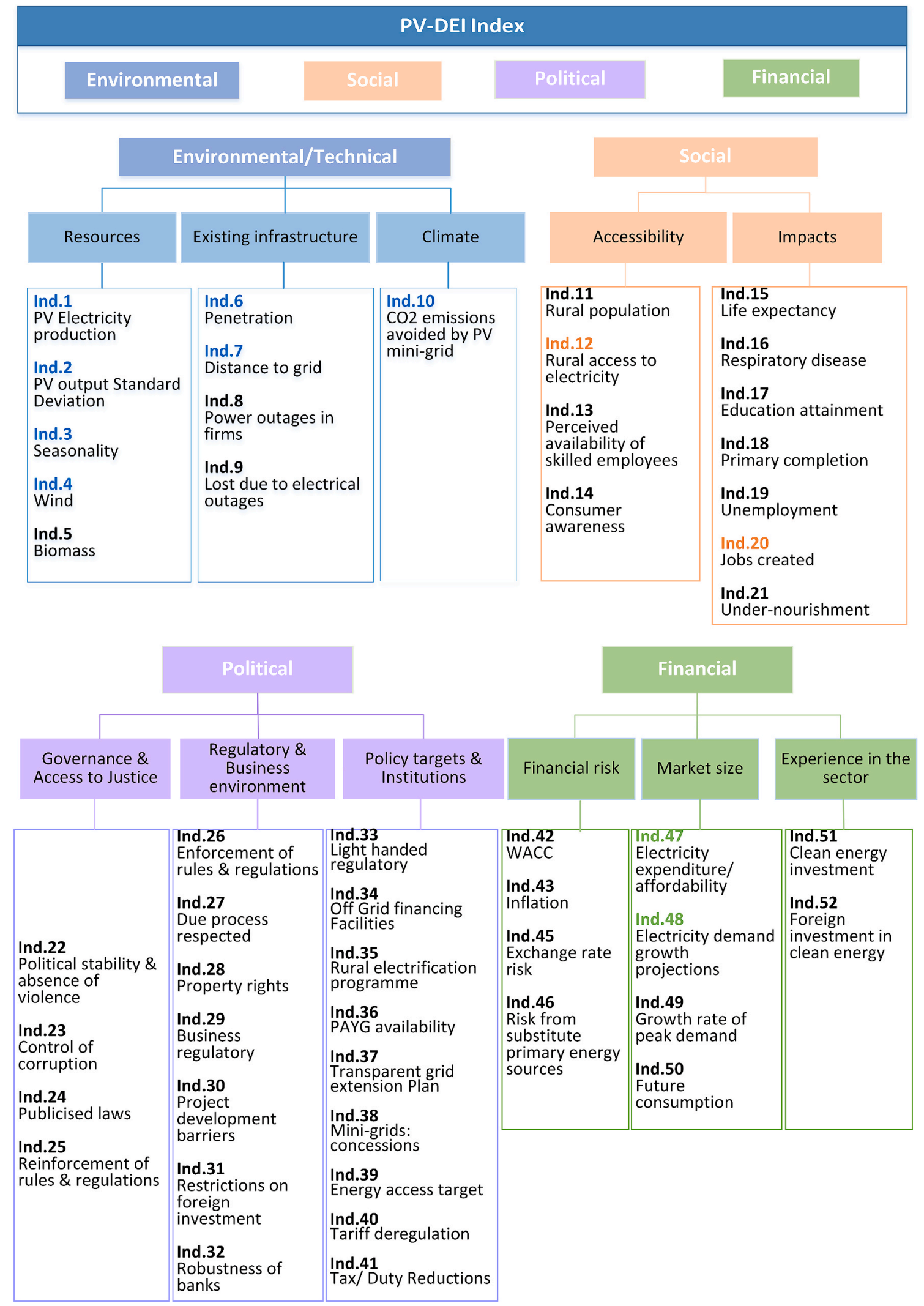

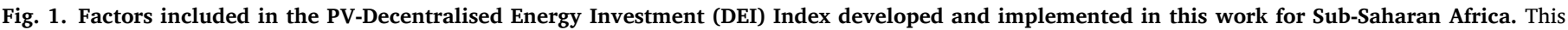

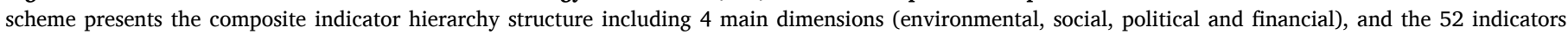

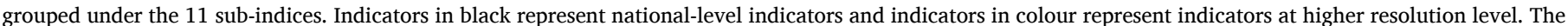
supplementary information includes the data sources and level of geographic detail available for each of these 52 indicators. 
composite indicator hierarchy).

The PV-DEI index was constructed following established best practice guidelines $[33,36]$. Correlation and principal component analysis were conducted to better understand the underlying structure of the PV-DEI index data. The weighting and aggregation of indicators was done in alignment with the theoretical framework, (Fig. 2, section 2.2, sections in S.I. 2 to S.I.5). Weights were multiplied by the country's score for each indicator, and then scores across all the 52 weighted indicators were summed together to produce a country's final index score.

\subsection{Effects of earth observation derived data to the indicator framework}

An innovation of the PV-DEI Index is that it consists of national-level indicators combined with high-resolution Earth Observation data and analytics. The data coverage for the African continent on population, settlement, energy services (production, consumptions, costs and payments) is fragmented. These data are crucial for off-grid electricity access planning and are not systematically collected in many countries, or collected in long intervals (i.e. census can be 10 year old), so remote sense data is an accessible approximation to minimise uncertainty and to reduce the current gaps in data availability.

These high-resolution indicators such as grid penetration, average distance of non-electrified population to existing grid, affordability factors, solar energy resource availability, $\mathrm{CO}_{2}$ emissions avoided by the PV mini-grid, number of jobs created by PV mini-grid installation and local energy demand (indicators in colour in Fig. 1), were estimated at 1 $\mathrm{km}^{2}$ resolution for the identified clusters of population without access to electricity. They were computed for areas receptive to decentralised options: populated areas further than $5 \mathrm{~km}$ from the existing grid, excluding areas where lighting was detected by satellite imagery (more details in SI).

Finally, the composite indicator analysis was complemented by a separate high-resolution $\left(1 \mathrm{~km}^{2}\right)$ spatial analysis of the levelised cost of electricity (LCOE) of decentralised-PV across SSA, in order to include the importance of local production cost. The estimated production cost of electricity ranged from 0.17 to $0.29 \mathrm{EUR} / \mathrm{kWh}$ SSA (see section 2.3). The
PV-DEI index and LCOE are aggregated to an intermediate sub-regional level by taking an equally-weighted average of national PV-DEI score and the average sub-regional LCOE value. Since some PV-DEI indicators are also available at high resolution, we additionally use this to perform an economic and technological analysis to evaluate the potential market for decentralised energy investment. The uncertainty of geospatial data aggregated at country level and how the accuracy can affect the results has been analysed in a number of previous studies [10,37-40]. The analyses showed the usefulness of adding remote sense data to mitigate uncertainties derived from the existing data gaps and to reduce the inaccuracies due to fragmented data coverage.

To summarise, the aim of this study is to provide a detailed map of suitable locations in SSA for decentralised solar-PV investments, considering local economic conditions (such as the LCOE), as well as social, financial, environmental, and political factors. Moreover, it can be used to identify the best performing countries or regions, in order to learn from the policies that may have contributed to the increased attractiveness of the country for DEI. The LCOE can also be used separately to quantify investment costs for selected locations/regions, helping to prioritise investments and policies within countries or even within sub-national regions.

\subsection{PV-DEI index methods}

\subsubsection{Structure of the PV-DEI index}

The construction of the PV-DEI index was based on a paradigm shift (away from an existing exclusive focus on LCOE analysis or alternative mono-dimensional qualitative measures), the authors believed necessary to evaluate the multiple dimensions along which stakeholders simultaneously assess a country's potential for PV decentralised deployment. The composite indicator was designed and developed to measure the multidimensional factors which cannot be captured by a single indicator, e.g. competitiveness, affordability and governance. The multidimensional factors were chiefly environmental/technical, social, political and financial considerations effecting stakeholder decisionmaking on PV mini-grid investments. Thus, these four categories form

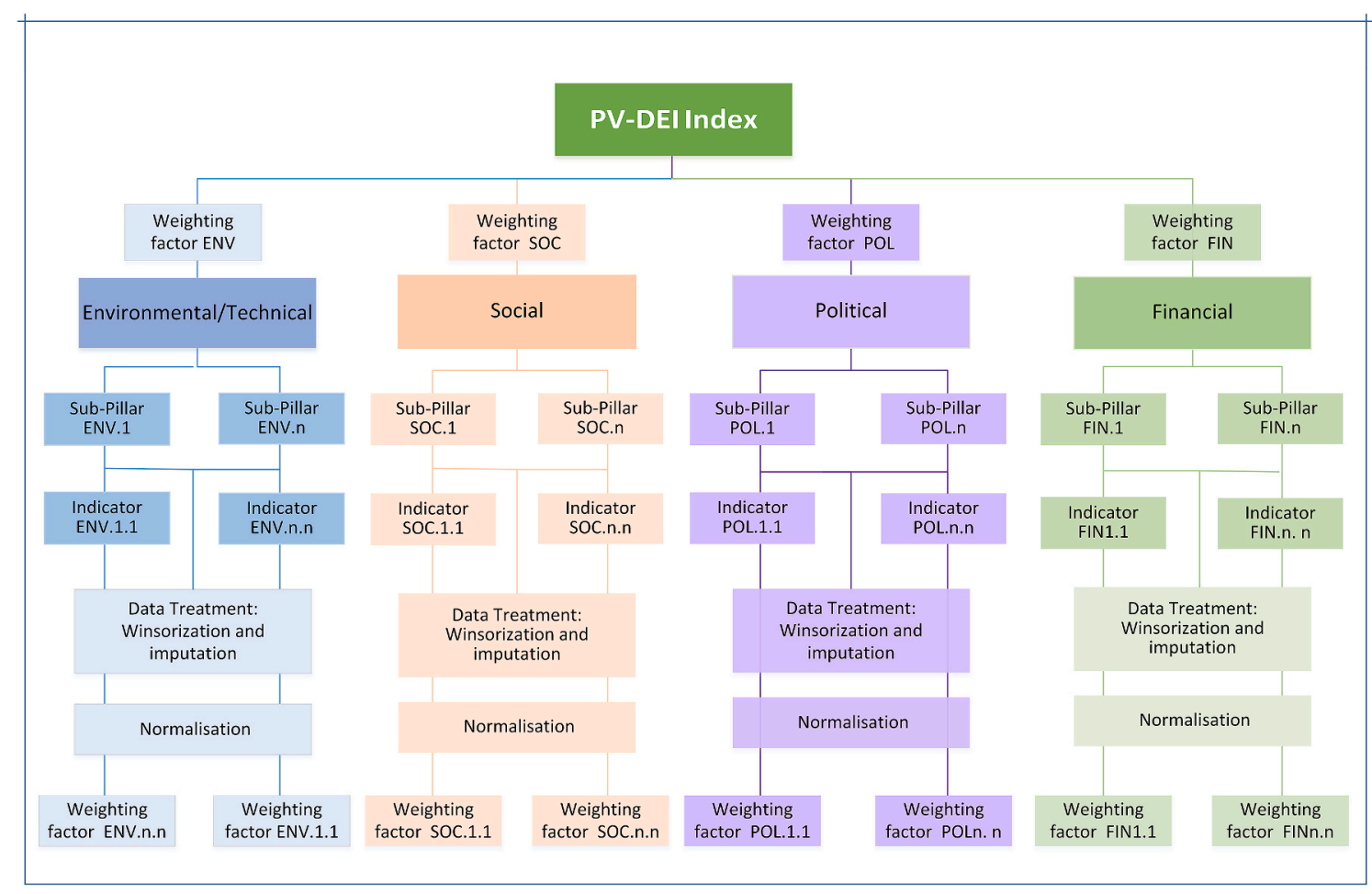

Fig. 2. Data treatment process followed in the construction of the PV-DEI index at country-level. 
a)

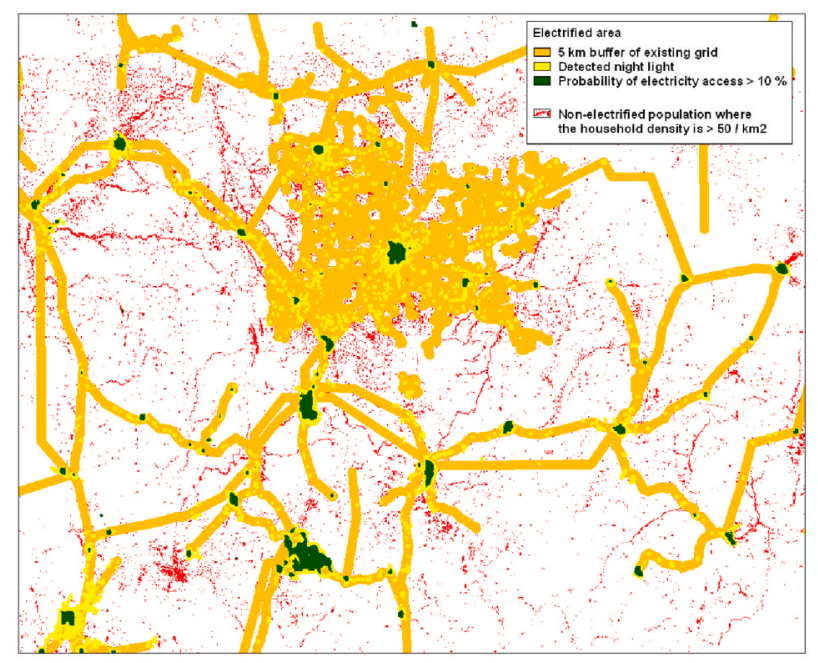

b)

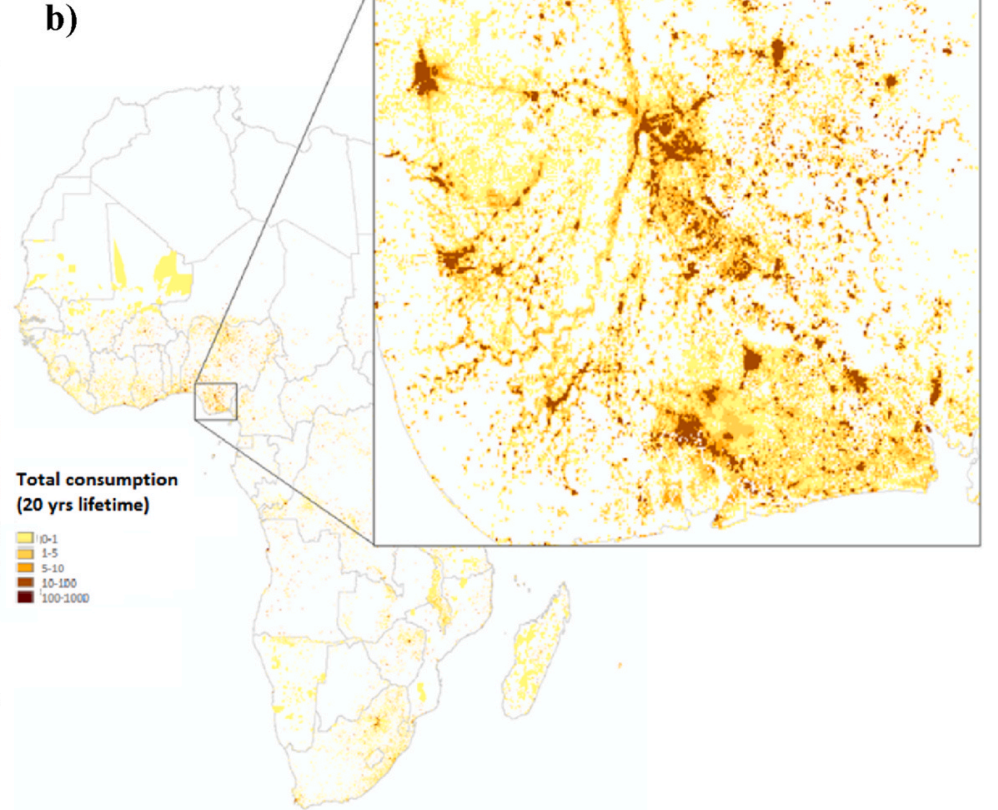

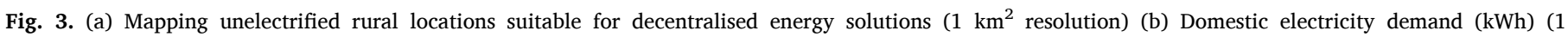
$\mathrm{km}^{2}$ resolution).

the pillars of the PV-DEI index.

In order to accurately reconcile these multiple dimensions within a composite indicator, the holistic structure of the PV-DEI index was informed by an extensive review of the existing literature, including whitepaper reports, academic papers and press releases which focused on specific sets of thematic indicators (see SI, Fig. SI1). The grouping of indicators within the pillars was informed by a stakeholder survey and continued review of the literature (Fig. 1, Table 1, Table SI1). The surveyed experts were selected from various governmental agencies, research institutions, private investors, financial institutions, and civil society organizations involved in the rural electricity sector in Africa.

Once the structure had been built in alignment with the existing literature and stakeholder expertise, and populated with indicators, the validation and robustness assessment of this structure was followed using correlational assessments and principal component analyses (detailed below). The PV-DEI index creation followed the 'best practice' for composite indicator design outlined by the European commission COIN service [41].

\subsubsection{Data selection}

Data selection was critical in determining the overall quality of the PV-DEI index composite indicator. The literature review and expert consultations were used to construct the hierarchical structure of the PVDEI index prior to data collection, to ensure selection was in alignment with the framework and not based on availability.

Indicators were chosen from reliable sources; where possible these were international organisations working under statistical regulations or codes of conduct. The quality of the data source was assessed using criteria defined by the International Monetary Fund (IMF) Data Quality Assessment [42]. This focused on the objectivity of the source in their collection and/or production of the data, methodological soundness in both data collection and processing, accuracy and reliability within the final data, the frequency and consistency of data updates, and accessibility. Accessibility was an important consideration as limitations here would compromise third parties' ability to investigate the original source material.

For the indicator data itself, quality was assessed using a combination of criteria outlined by the OECD/JRC European Commission in the
'Handbook on Constructing Composite Indicators' [33]. Following these guidelines ensured datasets were relevant to the overall purpose of the PV-DEI index, measured within an appropriate timeframe for the phenomenon of interest, appropriately sensitive to slight changes in this phenomenon, interpretable and complete with clear definitions of the items and/or populations studied, coherent across SSA countries, accurate and reliable (Table S.I and Table SI.II).

\subsubsection{Structural assessments}

To identify the underlying structure of the PV-DEI index, both correlational and principal component assessments (PCA) were conducted. Initial correlational investigations were conducted using the COIN tool [41] (Fig. SI.1) These correlational assessments were undertaken to ensure no two indicators within the same sub-pillar were highly correlated (high positive correlation: +0.5 ), rendering the use of one of them redundant. This was repeated to additionally ensure no indicators were negatively correlated with other indicators in their sub-pillar (high negative correlation: -0.5 ), which would have suggested an inconsistency between the indicators and what was being measured, with some indicators cancelling each other out Indicators that were either positively or negatively correlated with their neighbours were investigated to determine whether there was a theoretical grounding for this. If a theoretical grounding was discovered, and it was deemed relevant and necessary to retain the indicator because of the information it contained it was included in the index, and if not it was excluded. In the PV-DEI index only negative correlations were retained between indicators in the environmental sub-pillar (shown in red) however none of these exceeded -0.5 (Fig. SI.1).

PCA were conducted in addition to these correlational assessments, to visualise the underlying structure of the PV-DEI index (Fig. SI.2) PCA were undertaken to ensure that the grouping of indicators into subpillars and pillars was in alignment with the data, in addition to the qualitative stakeholder suggestions and literature review. This resulted in a refined composite indicator that is valid both qualitatively and quantitatively. To illustrate an example of how the index was refined using PCA, Indicator 48 which measures the removal of taxes and tariffs was moved from the financial dimension, to the political pillar that focuses on the creation of a decentralised energy market, based on the 
Table 1

List of the 52 composite indicators included in the PV-DEI index structured by 4 main pillars (environmental/technical, social, political and financial) and 10 subpillars.

\begin{tabular}{|c|c|c|c|c|c|}
\hline \multirow{3}{*}{$\begin{array}{l}\text { Pillar } \\
\text { Environmental/ } \\
\text { Technical p.1 }\end{array}$} & \multirow[b]{2}{*}{ sp.01 } & \multirow{2}{*}{$\begin{array}{l}\text { Sub-Pillar } \\
\text { Resources }\end{array}$} & \multicolumn{2}{|c|}{ Indicator Name } & \multirow{2}{*}{$\begin{array}{l}\text { Data Source } \\
\text { PVGIS, Huld et al. }[4,5]\end{array}$} \\
\hline & & & ind.01 & PV output - Country average & \\
\hline & & & ind.02 & PV output -Spatial variability & PVGIS, Huld et al. $[4,5]$ \\
\hline & & & ind.03 & Seasonality Indicator & PVGIS, Huld et al. $[4,5]$ \\
\hline & & & ind.04 & Wind resource Endowment & IRENA, DTU [6] \\
\hline & & & ind.05 & Biomass resource potential & IRENA, RFA [7] \\
\hline & sp.02 & Existing & ind.06 & Grid Penetration & Szabo et al. [8], NASA [9], \\
\hline & & Infrastructure & & & JRC-GHSL [10] \\
\hline & & & ind.07 & Distance from settlements to grid & $\begin{array}{l}\text { JRC-GHSL [10], Szabo et al. [8], } \\
\text { NASA [9], }\end{array}$ \\
\hline & & & ind.08 & Power Outages in firms in a Typical Month & World Bank [11] \\
\hline & & & ind.09 & Value lost due to electrical outages & World Bank [11] \\
\hline & sp.03 & Avoided Emissions & ind.10 & $\mathrm{CO}_{2}$ emissions avoided by the PV mini-grid instead of diesel mini-grid & Methods \\
\hline \multirow[t]{11}{*}{ Social p.2 } & sp.04 & Accessibility & ind.11 & Rural Population vs total population & World Bank [11] \\
\hline & & & ind.12 & Rural Access to electricity & World Bank [11] \\
\hline & & & ind.13 & Perceived availability of skilled Employees & Human Capital Index (WEF) [12] \\
\hline & & & ind.14 & Consumer Awareness - Lighting Africa Campaign & Lighting Africa [13] \\
\hline & sp.05 & Impacts & ind.15 & Life Expectancy at Birth & World Bank [11] \\
\hline & & & ind.16 & Respiratory Disease Incidence & WHO [14] \\
\hline & & & ind.17 & Education Attainment - Harmonized Test scores & World Bank [11] \\
\hline & & & ind.18 & Primary Completion Rate & World Bank [11] \\
\hline & & & ind.19 & Gender. Unemployment Rate - Female to Male Ratio & $\begin{array}{l}\text { UNDP Human development } \\
\text { Indicators [15] }\end{array}$ \\
\hline & & & ind.20 & $\begin{array}{l}\text { Estimated number of jobs created directly related to the deployment of } \\
\text { PV mini-grids }\end{array}$ & JRC-GHSL [10], OECD [16] \\
\hline & & & ind.21 & Prevalence of undernourishment as a percentage of the population & $\begin{array}{l}\text { International Food Policy Research } \\
\text { Institute [17] }\end{array}$ \\
\hline \multirow[t]{21}{*}{ Political p.3 } & sp.06 & Political & ind.22 & Political Stability and Absence of Violence/Terrorism & World Bank Worldwide \\
\hline & & Environment & & & Governance Indicators [18] \\
\hline & & & ind.23 & $\begin{array}{l}\text { Control of Corruption as the risk that companies will face bribery or } \\
\text { other corrupt practices }\end{array}$ & $\begin{array}{l}\text { World Bank Worldwide } \\
\text { Governance Indicators }\end{array}$ \\
\hline & & & ind.24 & $\begin{array}{l}\text { Publicised Laws: Whether basic laws and information on legal rights are } \\
\text { publicly available }\end{array}$ & World Justice Project [19] \\
\hline & & & ind.25 & $\begin{array}{l}\text { Complaint redress mechanisms: people able to bring specific complaints } \\
\text { to government about provision of public services }\end{array}$ & World Justice Project [19] \\
\hline & & & ind.26 & Government regulation effectively enforced & World Justice Project [19] \\
\hline & & & ind.27 & Due Process is respected & World Justice Project [19] \\
\hline & & & ind.28 & $\begin{array}{l}\text { Property Rights: No unlawful expropriation without adequate } \\
\text { compensation }\end{array}$ & World Justice Project [19] \\
\hline & & & ind.29 & Business Regulatory Environment & $\begin{array}{l}\text { Ibrahim Index of African } \\
\text { Governance IIAG [20] }\end{array}$ \\
\hline & & & ind.30 & Project Development Barriers & ClimateScope [21] \\
\hline & & & ind.31 & Absence of Restrictions on Foreign Investment & $\begin{array}{l}\text { Ibrahim Index of African } \\
\text { Governance [20] }\end{array}$ \\
\hline & & & ind.32 & Robustness of Banks & $\begin{array}{l}\text { WEF Global Competitiveness } \\
\text { Report [22] }\end{array}$ \\
\hline & sp.07 & & ind.33 & Light Handed regulatory framework & ClimateScope $[21]$ \\
\hline & Decent & alised Energy & ind.34 & Off Grid Financing Facilities & ClimateScope [21] \\
\hline & Market & & ind.35 & $\begin{array}{l}\text { Rural Electrification Programme: rewards countries where a detailed } \\
\text { rural electrification program is in place }\end{array}$ & ClimateScope [21] \\
\hline & & & ind.36 & Availability of Pay As You Go (PAYG) solar technologies & ClimateScope [21] \\
\hline & & & ind.37 & Transparent Grid Extension Plan & ClimateScope [21] \\
\hline & & & ind.38 & Mini-grids concessions & ClimateScope [21] \\
\hline & & & ind.39 & Off-grid energy access target & ClimateScope [21] \\
\hline & & & ind.40 & $\begin{array}{l}\text { Tariff deregulation: off-grid developers can structure the tariffs they } \\
\text { charge for their electricity themselves }\end{array}$ & ClimateScope [21] \\
\hline & & & ind.41 & Tax/Duty Reductions: renewables benefit of reductions in tax and duties & ClimateScope [21], IRENA [23], \\
\hline \multirow[t]{11}{*}{ Financial p.4 } & sp.08 & Financial Risk & ind.42 & Weighted Average Cost of Capital (WACC) & Ondraczek et al. [24] \\
\hline & & & ind.43 & Inflation consumer prices (annual \%) & IMF [25] \\
\hline & & & ind.44 & $\begin{array}{l}\text { Exchange Rate Risk measured the volatility in the exchange rate within } \\
\text { each country }\end{array}$ & World Bank [11] \\
\hline & & & ind.45 & Cost of fuel incumbents: Pump price for diesel fuel & World Bank [11] \\
\hline & & & ind.46 & Current electricity generation from fossil fuels & The Shift Project [26] \\
\hline & sp.09 & Market Size & ind.47 & Electricity Expenditure Per Day & World Bank [11], JRC [27] \\
\hline & & & ind.48 & Electricity demand growth (10 year projection) & ClimateScope [21] \\
\hline & & & ind.49 & Growth Rate of Peak demand (5 year average) & ClimateScope [21] \\
\hline & & & ind.50 & Consumption modelled for universal access to electricity & Methods section \\
\hline & sp. 10 & Experience in the & ind.51 & Clean energy Investments & ClimateScope [21] \\
\hline & & sector & ind.52 & Foreign investment in Clean energy & ClimateScope [21] \\
\hline
\end{tabular}


results of an intermediary principal component analysis. This remained in keeping with the conceptual framework of the political dimension. The structural assessments detailed here were repeated after each data treatment to understand the effects these were having on the overall structure of the index. For more detail on the PCA and correlational assessments please see the supplementary materials.

\subsubsection{Data treatment: data intensification, outliners' treatment and imputation of missing data}

The processes used in the construction of the PV-DEI index were capable of distorting the obtained results. Therefore, great care was taken to investigate the implications of choices made regarding normalisation techniques, imputation of missing data, and the weighting and aggregation procedures.

Initially we ensured indicators were comparable across SSA countries with diverse population sizes, land areas, and natural resources. This necessitated the intensification [36] of appropriate indicators: For example, raw data on total number of jobs created was intensified by dividing by the country's labour-force population, to make this indicator comparable across countries with disparate working populations.

The distribution of the indicator statistics can be heavily influenced by outliers. Winsorization was used to remove extreme outliers. Following the protocol in the COIN tool [36], data sets were winsorized when skew was greater than 2 (high degree of distortion from the normal distribution) and kurtosis (measure of outliers present in the distribution) was greater than 3.5. In total, nine out of the 52 indicators included in the PV-DEI index were winsorized. A sensitivity assessment was conducted to examine the effects of winsorization on PV-DEI index scores (Fig. SI.3).

Following winsorization the challenge of missing data was addressed. Initially, countries with data coverage lower than $65 \%$ across the 52 indicators were removed. Two methods were then assessed for imputing missing values:

i) Multiple Imputation via Chained Equations (MICE)

ii). Implementation of a random forest algorithm (MissForest).

In the final index the MissForest package was used. This made fewer assumptions about the shape of each data-set and did not require a specific regression model to be specified for imputation; instead it used a technique that was capable of modelling non-linearities between variables. In contrast MICE used linear regressions a priori to predict continuous missing data-points from the existing data, however the 'true' imputation model may have contained non-linearities. When reassessing the correlations between variables following each imputation method using the COIN tool [41], the MissForest method (Fig. SI.5) preserved the original relationships between the variables better than the MICE technique (Fig. SI.4). This result is in alignment with the findings of Shah et al. [43], who found that a random forest technique was more efficient than default MICE methods, and produced narrower confidence intervals when looking at complex datasets. Our research therefore also lends additional support for their hypothesis.

For the 11 categorical variables included in the index the mode of the region of SSA in which the country was located was used to impute any missing values. This is in alignment with the best practice for handling missing categorical data. The data was then quantised by assigning the maximum value of 1 to 'yes' answers, 0.5 to 'somewhat' answers and 0 to 'no' answers; this would be reversed in the case of negatively weighted indicators. For example, in response to the Climatescope2018 survey question on the presence of a rural electrification programme, countries that responded 'yes' would score 1 , 'somewhat' would score 0.5 and 'no' would score 0 .

The completed data sets were normalised to ensure comparability between indicators that existed at different scales and ranges and were measured in disparate units. The rescaling or min-max method of normalisation was chosen as this preserved the shape of the data distribution for each indicator, and did not unduly reward or punish exceptional indicator values in contrast to standardisation using Zscores (Fig. SI.6). Using the rescaling technique all indicators had the same range. Therefore, the influence of indicators with smaller natural intervals were exaggerated within the composite indicator. However, due to winsorization within the COIN tool the intervals of all the datasets were less disparate. The smallest intervals were on indicators such as life expectancy, which had a mean of 62.28 and a standard deviation of 5.09. Due to the value placed on a human life the enhanced disambiguation of countries with respect to this variable was not discouraged. As shown in Fig. SI.6, the choice of normalisation technique did not significantly distort the ranking of countries within the PV-DEI index.

\subsubsection{Weighting the composite indicator}

Other combined metrics, such as the World Bank's 'Ease of Doing Business' (EODB) [44], have weighted all indicators equally without a stated justification for this decision. In this paper an equal weights approach was not selected as the authors did not desire direct compensability between indicators, due to some indicators having greater importance for directing investment in decentralised solar-PV.

Mirroring the methods used in the creation of the structure of the PVDEI index, the weighting of indicator scores was done in alignment with a theoretical framework based on an extensive literature review and expert consultations (see Refs. $[35,45,46]$ and SI), and detailed principal component analyses conducted at the sub-pillar level of the composite indicator hierarch.

Explicitly, principal component analyses were used to determine the relative loadings of individual indicators within sub-pillars. Indicators that loaded most highly onto the first principal component for a given sub-pillar were judged to be in greater alignment with the over-all subpillar measure, and weighted to reflect their greater relevance, (checking, that this made sense theoretically and was in keeping with the stakeholder elicitation). For example, the first principal component for the sub-pillar 'Regulatory and Business Environment' (comprised of indicators 26 to 32) is shown in Fi SI.7. In accordance with the authors evaluation of the first principal component, and as evidenced in a review of the relevant literature, the importance of property rights (Indicator 28) was weighted more highly that other indicators within this pillar. This process was repeated to weight the individual indicators within all the sub-pillars (See supplementary materials).

At higher levels of the PV-DEI the importance of the pillars were evaluated using a stake-holder elicitation survey, to determine how important broad categories of indicators e.g. Social or Financial were to different individuals wishing to use the index. Weights were multiplied by the country's score for each indicator, and then scores across all the 52 weighted indicators were summed together to produce a country's final index score (weights and detailed methodology included in SI).

The authors acknowledge that the scores obtained from the PV-DEI index are highly dependent on the weighting system chosen, in this paper sensitivity assessments have been conducted using weights selected that represented private finance, international donors and governments, and philanthropic perspectives. These were obtained from the different participants in the stakeholder elicitation. Fig. 5 illustrates how results were contingent on the weights selected in these different perspectives.

\subsection{Net present value calculations and levelised cost of electricity model}

The levelised cost of electricity (LCOE) of solar decentralised technologies was geospatially assessed across Sub-Saharan Africa and embedded into the "big picture" given by the composite indicator either economic, environmental/technical, social or political dimensions. To calculate LCOE for PV mini-grids with battery storage, the model estimates the performance of the PV mini-grid overall geographical populated areas in Sub-Saharan Africa at $1 \mathrm{~km}^{2}$ spatial resolution. The total amount of solar irradiation, the intermittency of the solar irradiation 
and the electricity demand depend strongly on location. Therefore, the same PV array and battery storage arrangement may be over dimensioned for some locations and undersized in others. The algorithms optimize the PV array and battery storage size for a given populated location ( $1 \mathrm{~km}^{2}$ cell) ensuring a frequency of power outage less than $5 \%$ of days. The methodology consists of geospatial analysis of the energy output and reliability of PV mini-grid system described in detail and validated in Refs. [47-49]. These methods have been adapted here to include also the estimated electricity residential consumption in the populated areas. The algorithm (detailed description in A) uses a combination of hourly solar radiation data from satellites combined with temperature and wind speed data from reanalysis, and population distribution and density data [50]. The specific algorithm also incorporates measured data on PV module and battery performance using Li-ion batteries instead of the traditional lead-acid batteries [48] and the estimated electricity consumption data per $1 \mathrm{~km}^{2}$ cell (supplementary material).

The levelised cost of electricity LCOE for PV mini-grids for each location is calculated by 20 years lifetime taking into the account the distribution and density of population per cell $\left(1 \mathrm{~km}^{2}\right)$. The LCOE calculation involves local techno-economic assumptions including daily data of solar resource [51,52], upfront costs, lifetime of PV modules and batteries, etc. (detailed description in SI). To estimate the LCOE values, the model makes use of capital costs including economy of scales (Table 2). To calculate the LCOE the costs of installation, distribution, operation and maintenance are taken into consideration by the following equation:

$$
\begin{aligned}
\operatorname{LCOE}_{\mathrm{n}}= & \frac{\operatorname{CAPEX}_{0}+\sum_{\mathrm{t}=1}^{T}\left\{\left(\mathrm{R}_{\mathrm{t}}+\mathrm{O}_{\mathrm{t}}\right) /\left(1+\mathrm{r}_{\mathrm{n}}\right)^{\mathrm{t}}\right\}}{\sum_{\mathrm{t}=1}^{\mathrm{T}}\left\{\left(\mathrm{ES}_{\mathrm{n}}\right) /\left(1+\mathrm{r}_{\mathrm{n}}\right)^{\mathrm{t}}\right\}} \\
\text { CAPEX }_{0}= & \sum_{n=1}^{N}\left[\left(P V_{K W_{n}} * P V_{E^{\prime} U R_{n}}\right)+\left(P V_{K W_{n}} * \text { BOS }_{E U R_{n}}\right)\right. \\
& \left.+\left(B A T_{K W h_{n}} * B A T_{E U R_{n}}\right)+\left(\text { Cons }_{n} * \text { line }_{\frac{E U R}{k W h_{n}}} * \text { Ncells }_{n}\right)\right]
\end{aligned}
$$

Where:

\section{$\mathrm{n}$ : PV mini-grid zone}

$L C O E_{n}$ : levelized cost of electricity in location $\mathrm{n}$ [EUR/kWh]

CAPEX $X_{0}$ : initial PV mini-grid investment cost at $\mathrm{t}=0$ [EUR]

$\mathrm{t}$ : time in years $\mathrm{t}=0$ is the installation year
T: economic lifetime of the PV mini-grid [years]

$\mathrm{O}_{\mathrm{t}}$ : operation and maintenance cost in year $\mathrm{t}$ [EUR]

$\mathrm{R}_{\mathrm{t}}$ : replacement cost in year $\mathrm{t}$ [EUR]

Cons $_{n}$ : average annual electricity consumption in location $n$ [kWh]

$\mathrm{ES}_{\mathrm{n}}$ : average annual electricity production from the given system depending on solar radiation and population in location $\mathrm{n}[\mathrm{kWh}]$

$r_{n}$ : discount rate in location $n$

The initial PV mini-grid investment cost were calculated for each PV mini-grid zone (aggregated cells following criteria in section consumption). For each PV mini-grid zone, the total PV size $\left(P V_{K W_{n}}\right)$ and battery size $\left(B A T_{K W h_{n}}\right)$ were determined, and then the up-front cost per component were calculated by the effect of the economies of scale (Table 2).

The annual energy output [kWh/year] has been calculated for each pixel $1 \mathrm{~km} \times 1 \mathrm{~km}$ using a combination of several models [48], a model for effective irradiance with solar radiation measured from satellites, a PV output power model with measured data on module performance, and a model for battery performance based on measured battery data. The baseline effectively produces a snapshot of the technology allocation for connecting the current population using current PV mini-grid technologies. For the baseline, the model runs under the most conservative assumptions, considering as a priority energy access but not considering the effects of industrialization per settlement. The baseline takes into account the current situation without projections on population growth, and without projections on increase of consumption.

\subsubsection{Consumption calculations}

The study focuses on detecting suitable sites to bring electricity by decentralised options to population without access to electricity in SubSaharan Africa. The lack of availability to harmonized geodata of African settlements and the inconsistent demographic information produced through census campaigns and released in aggregate form by UN has promoted the science community to invest in extracting information from the available satellite remote sensing archives and plan to process future incoming imagery [54]. Since the most accurate geographic distribution of the population is essential for determining where the population has no access to electricity, the latest integrated continental dataset the population distribution provided by the Global Human Settlement Layer (GHSL) framework [55] was applied in the study. The new algorithm surveys remote areas where the population is most likely without access to electricity. A combination from multiple sources was use to compile the dataset of the existing grid (OSM, WB datasets, Arderne et al. [56], ECOWREX [57] and from rural electrification agencies/EU delegations (Burkina Faso [58], Kenya [49], Tanzania [59, 60]). The population layer was spatially combined by the $5 \mathrm{~km}$ buffer

\begin{tabular}{|c|c|c|c|c|c|}
\hline & \multicolumn{3}{|l|}{ Economies of scale } & \multirow[t]{2}{*}{ Lifetime [years] } & \multirow[t]{2}{*}{ Discount rate [\%] } \\
\hline & PV Size $<1 \mathrm{~kW}_{\mathrm{p}}$ & $5 \mathrm{kWp}<$ PV Size $<15 \mathrm{~kW}_{\mathrm{p}}$ & PV Size $\geq 100 \mathrm{~kW}_{\mathrm{p}}$ & & \\
\hline $\mathrm{PV}$ module $\left[\mathrm{EUR} / \mathrm{kW}_{\mathrm{p}}\right]$ & 996 & 830 & 664 & 20 & 5 \\
\hline Balance-of-system $\left[\mathrm{EUR} / \mathrm{kW}_{\mathrm{p}}\right]$ & 1200 & 1000 & 800 & & \\
\hline Distribution lines [EUR/kWh $/ \mathrm{km}$ ] & $\begin{array}{l}\mathrm{HH} \leq 50 \\
\text { Distribution cost not included (SHS) }\end{array}$ & $\begin{array}{l}100<\mathrm{HH}<50 \\
0.025\end{array}$ & $\begin{array}{l}\mathrm{HH} \geq 100 \\
0.02\end{array}$ & 20 & 5 \\
\hline Li-ion battery [EUR/kWh nominal] & $\begin{array}{l}\text { Battery capacity } \leq 50 \mathrm{kWh} \\
350\end{array}$ & & $\begin{array}{l}\text { Battery capacity }>50 \mathrm{kWh} \\
280\end{array}$ & 10 & 5 \\
\hline
\end{tabular}

Table 2

PV mini-grid component costs including economies of scale and dependency according to the household density (HH) The component costs.

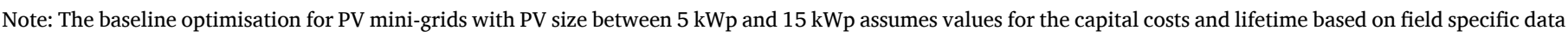
(2018) [53] and a low discount rate (5\%) compare to the rate given to traditional energy infrastructure. ${ }^{\text {a }}$ Solar Home Systems (SHS).

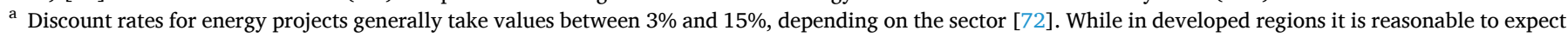

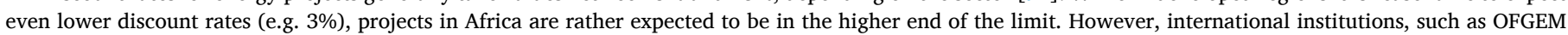

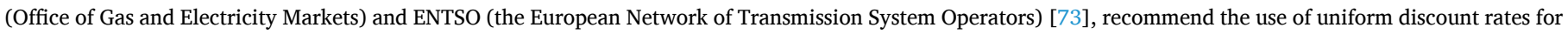

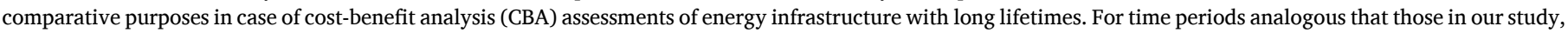

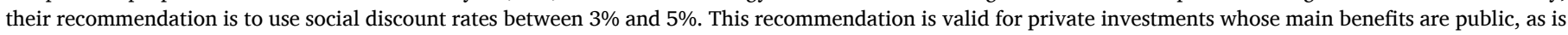
the case in this study [74].. 

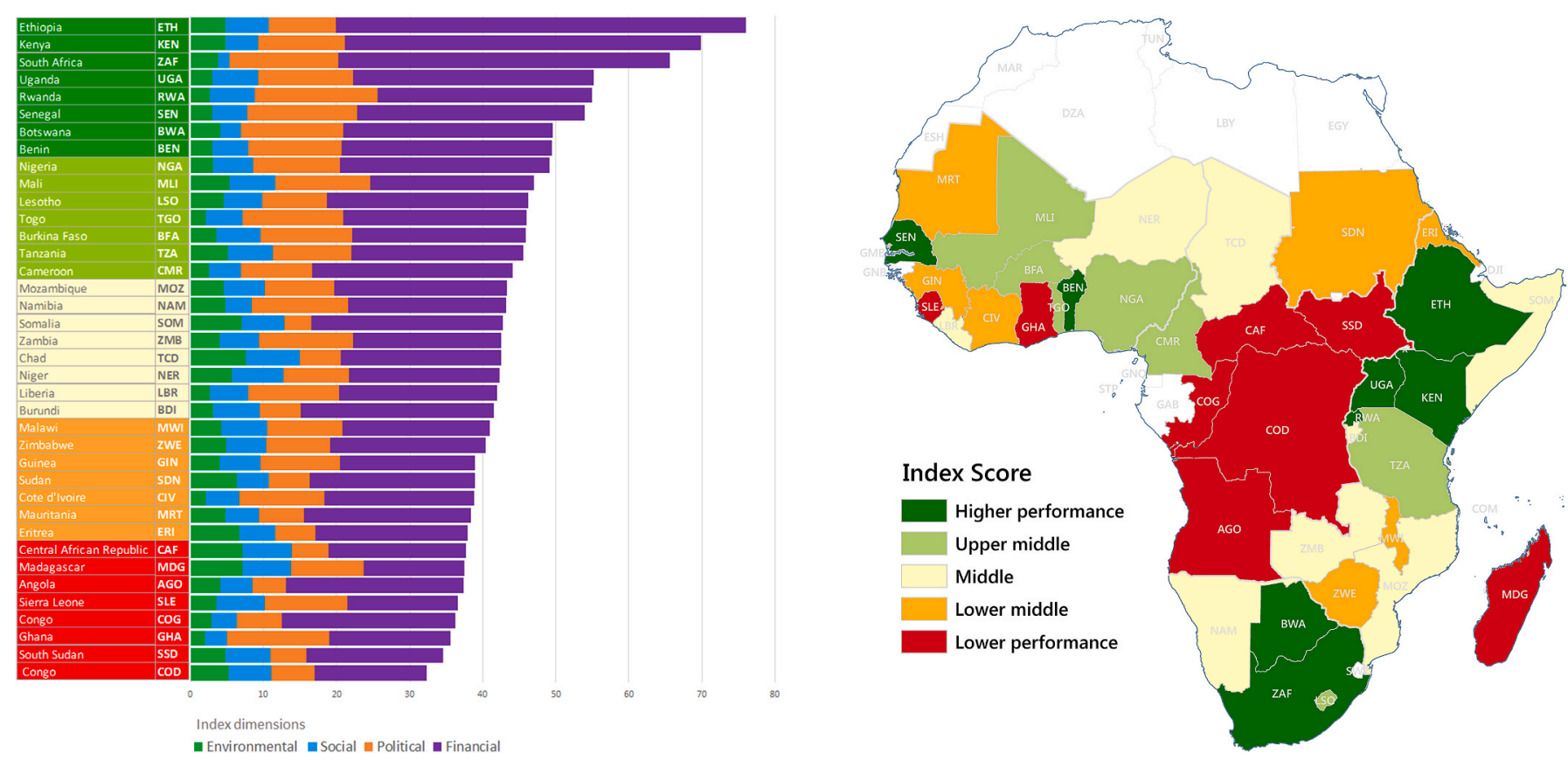

Fig. 4. (a) Sub-Saharan Africa map with the PV-DEI index score for each country computed for the private sector approach: From highest performance (in dark green) to lowest performance (in dark red). The colour scheme is divided in five ranges, separated at the values of the $20^{\text {th }}, 40^{\text {th }}, 60^{\text {th }}$, and $80^{\text {th }}$ percentiles. (b) Country-level ranking and breakdown of index with share of the four main dimensions (Environmental, Social, Political and Financial).

area of already existing electricity grid, the NASA nighttime lights imagery (Lighted area as a subset of the NASA image compiling data captured by a sensor aboard the NASA-NOAA Suomi NPP satellite) [61] and the geostatistical probabilistic layer on household electricity access in Africa [40,62,63].

The GHSL builds on past experiences and on different resolution settlement products and reports on processing 40 years of Landsat imagery for mapping the global built-up areas from 1975 to 2015 [55]. The number of population allocated in each $1000 \mathrm{~m} \times 1000 \mathrm{~m}$ cell derives from GHSL associated to the GHS-POP data [55]. The population grid datasets GHS-POP are derived from the GHSL building density and population census data and originally developed in order to reallocate census population to built-up areas. A multi-criteria site-selection algorithm was designed to identify the populated areas without access to electricity. The criteria used to delineate the electrified areas were:

i) Populated areas located within a $5 \mathrm{~km}$ distance to the existing electricity grid.

ii) Settlements with detected night time light (based on the NASA satellite with $1 \mathrm{~km}^{2}$ resolution).

iii) Areas where the probability of a household having electricity is higher than $10 \%$ [62].

iv) In order to select the areas where PV mini-grids are favourable, we selected the population living out of the delineated "electrified buffer" and aggregated the neighbour population for contiguous grid cells. The cells fulfilling the above criteria (out of the buffer) and with household density larger than $50 \mathrm{HH} / \mathrm{km}^{2}$ $(\mathrm{HH}>50)$ were selected followed by an aggregation function with an 8-direction connectivity criteria of the adjacent cells. In this way, we proceed in a differentiation for decentralised options between PV stand-alone systems and PV mini-grids in relation to the density of population and size of the PV system corresponding to the aggregated cells. As a result, each group of cells form one individual zone representing unique load centre for the communities with independent PV mini-grids or PV stand-alone systems. v) For each of the individual zones the PV systems are optimized by the algorithms described in A. When the resulting PV size is larger than $1 \mathrm{MW}_{\mathrm{p}}$ then is not considered as a decentralized solution.

Validation of the applied model has been completed by partially available settlement data and visual interpretation of satellite images. The modelling exercise identified 87,258 potential PV decentralised options covering a total population about 176 million people.

The total peak demand for each identified cell with population without access to electricity is estimated by summing up domestic demands and a coincidence factor of 70\% [49]. Each load consumption is calculated per cell depending on the allocated population GHSL, the index of poverty of the corresponding country, the social infrastructure, the contribution of productive use in relation to the poverty and unemployment indexes. The domestic electricity load per populated pixel is calculated following the assumption that residential sector is the dominant costumer group. The total electricity residential consumption per settlement is calculated by the number of household ( $\mathrm{HH}$ ) depending on the average people per household of each country. The electricity consumption per household are chosen to be consistent with two of the multi-tier matrix Tier 3 and Tier 4 used in the Sustainable Development Goal 7 (SDG7) for measuring access to household electricity supply [48, 64]. The SDG multi-tier matrix range from Tier 0 no access to electricity to Tier 5 the highest level of consumption, $\geq 3000 \mathrm{kWh} /$ year/HH [64].

\section{Results}

\subsection{National scoring on attractiveness to investment in decentralised technologies}

The PV-DEI index and accompanying LCOE data were designed as a flexible tool to support the mobilisation of sustainable investment from either the private, public, non-for profit, and international sectors. The multidimensional framework of the composite indicator has the advantage of being malleable to different stakeholder priorities by adjusting the weights of individual indicators and aggregation. This is implemented in a new web-based tool where stakeholder priorities can 

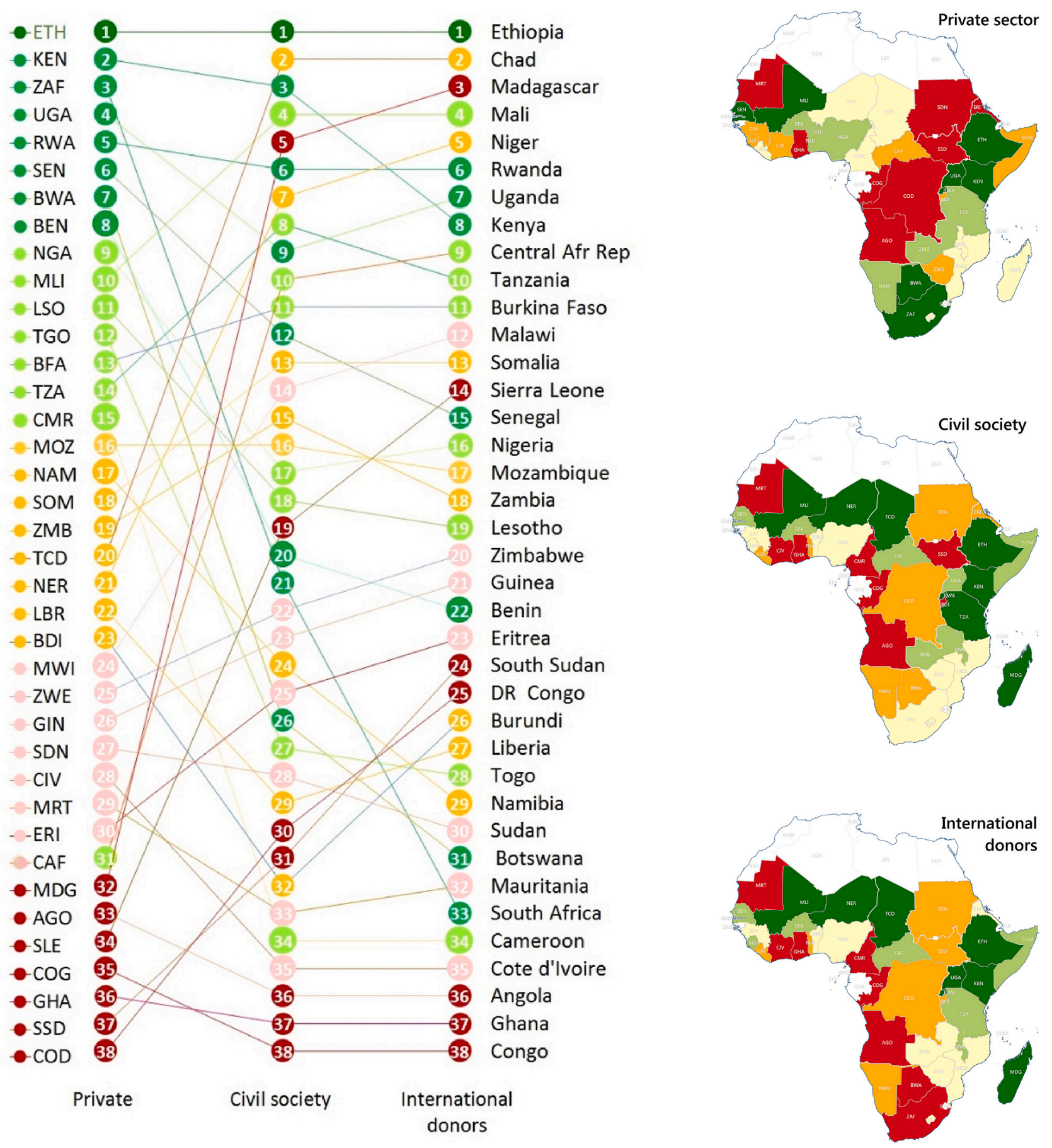

Fig. 5. Al Effect of the ranking of countries depending on the three stakeholder approaches. B | Spatial distribution of the PV-DEI index for private sector, civil society and international donor approach. White background indicates countries in which composite indicator function is not statistically robust.

be reflected by user-specified weights (SI).

In this paper however we focus on scoring and analysis under weighting priorities pertinent to the private sector, determined through expert consultations ([35] and SI). In six of the SSA countries, the results of the analysis are not shown due to the lack of reliable data (Djibouti, Gambia, Guinea Bissau, Equatorial Guinea, Gabon and Eswatini).

The emerging overall picture of the county level PV-DEI (Fig. 4) is that Eastern and Southern African countries (6 of the 8 top countries) scored significantly better than central African countries. In the west region, results were more heterogeneous with countries such as Senegal and Benin performing well, while other countries such as Ghana and Sierra Leone scored poorly. The five best scores were those for Ethiopia,
Kenya, South Africa, Uganda and Rwanda. Two of the 8 top countries were located in Western Africa; Senegal and Benin. At the other end, 4 out of the 8 lowest scores are in Central Africa, with the five lowestranking being Sierra Leone, Congo, Ghana, South Sudan and the Democratic Republic of the Congo. The lower end of the scale includes, not surprisingly, countries experiencing prolonged and recurrent financial and political instability and conflict, such the Democratic Republic of the Congo, which is emerging from political crisis and civil war. Wellperforming countries have relatively solid commercial and financial bases such as Kenya and South Africa. An important indicator in these rankings is the market size in each country defined as the off-grid population with not yet access to electricity in absolute terms. As the PV-DEI 
a)

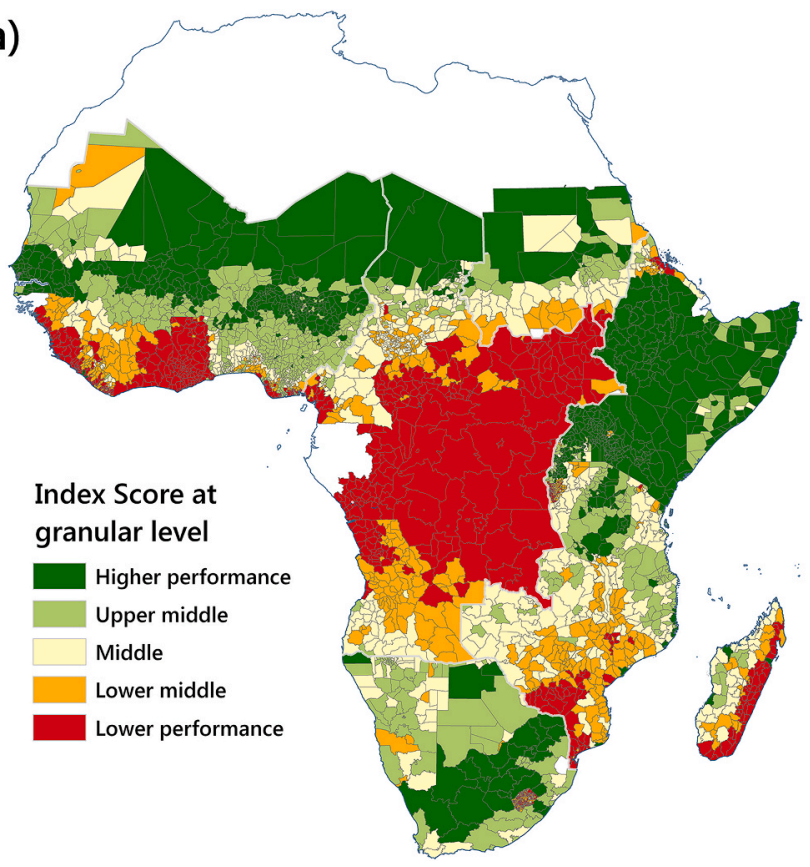

b)

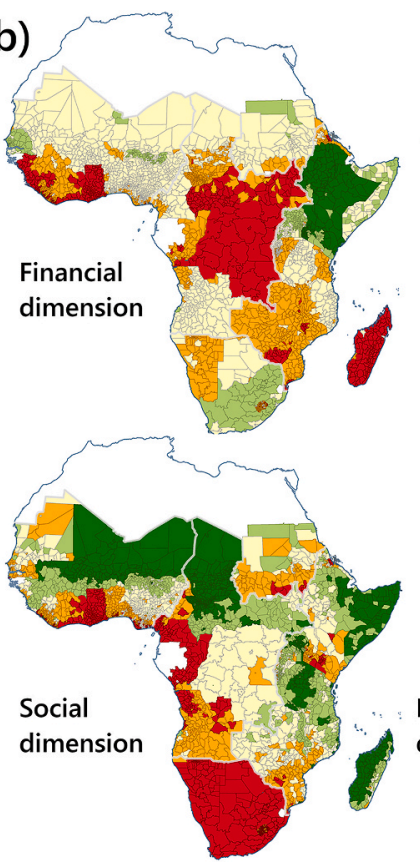

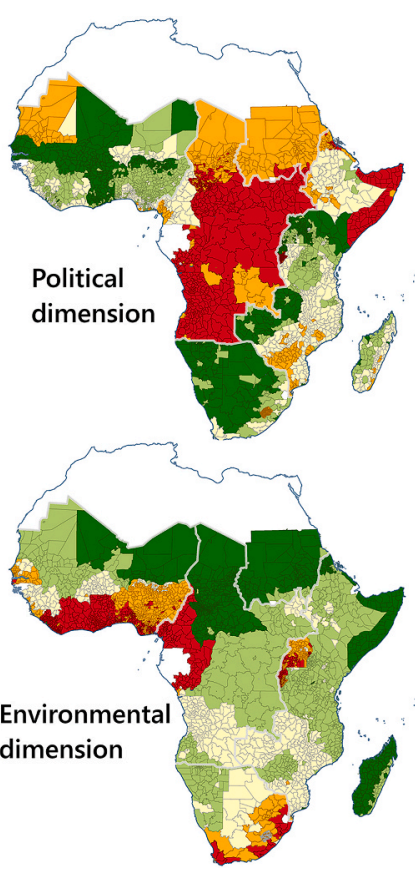

Fig. 6. a) Spatial distribution of PV DEI index computed with the LCOE at sub-regional level. The composite indicator captures sub-national differences within countries to determine whether there was a privileged part in the country specifically for decentralised option and country-level socio-economic indicators that are unequally distributed. To facilitate the overview and understanding of data distribution the percentile method the colour scheme is divided in five ranges, separated at the values of the $20^{\text {th }}, 40^{\text {th }}, 60^{\text {th }}$, and $80^{\text {th }}$ percentiles (from dark red to dark green). b) Spatial distribution of the environmental, social, political and financial dimensions computed with the LCOE at sub-regional level. Each of the dimensions capture sub-national differences within countries specifically for each of the dimensions that are unequally distributed, therefore highlighting the scoring of the 4 dimensions independently Investments and market size per country.

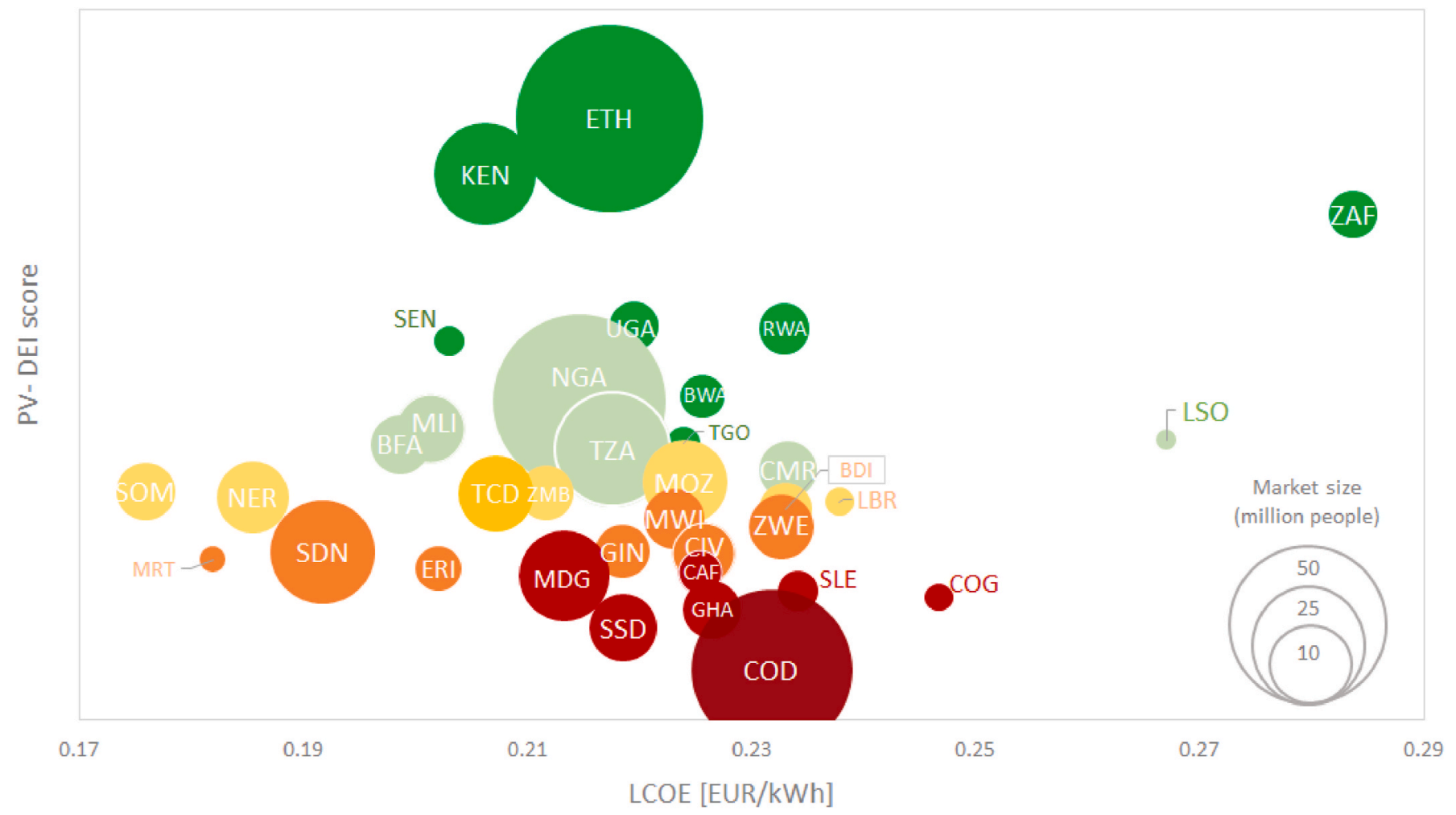

Fig. 7. Country performance versus production cost including market size. Interlinkage of selected social and economic indicators aggregated from high-spatial resolution to country-level. Identification of countries which add the most value to investment portfolio and presents higher investment suitability: countries with lower LCOE, larger market size, and high PV-DEI performance. The LCOE is calculated as an average of the LCOE $1 \mathrm{~km}^{2}$ resolution values per country taking only the areas covered by decentralised options. Circles are shaded by PV-DEI index scores (lower performance in red and higher performance in green). The size of the bubble serves as an indication of the market size per country. The market size represents the amount of population living in areas favourable to decentralised energy. 


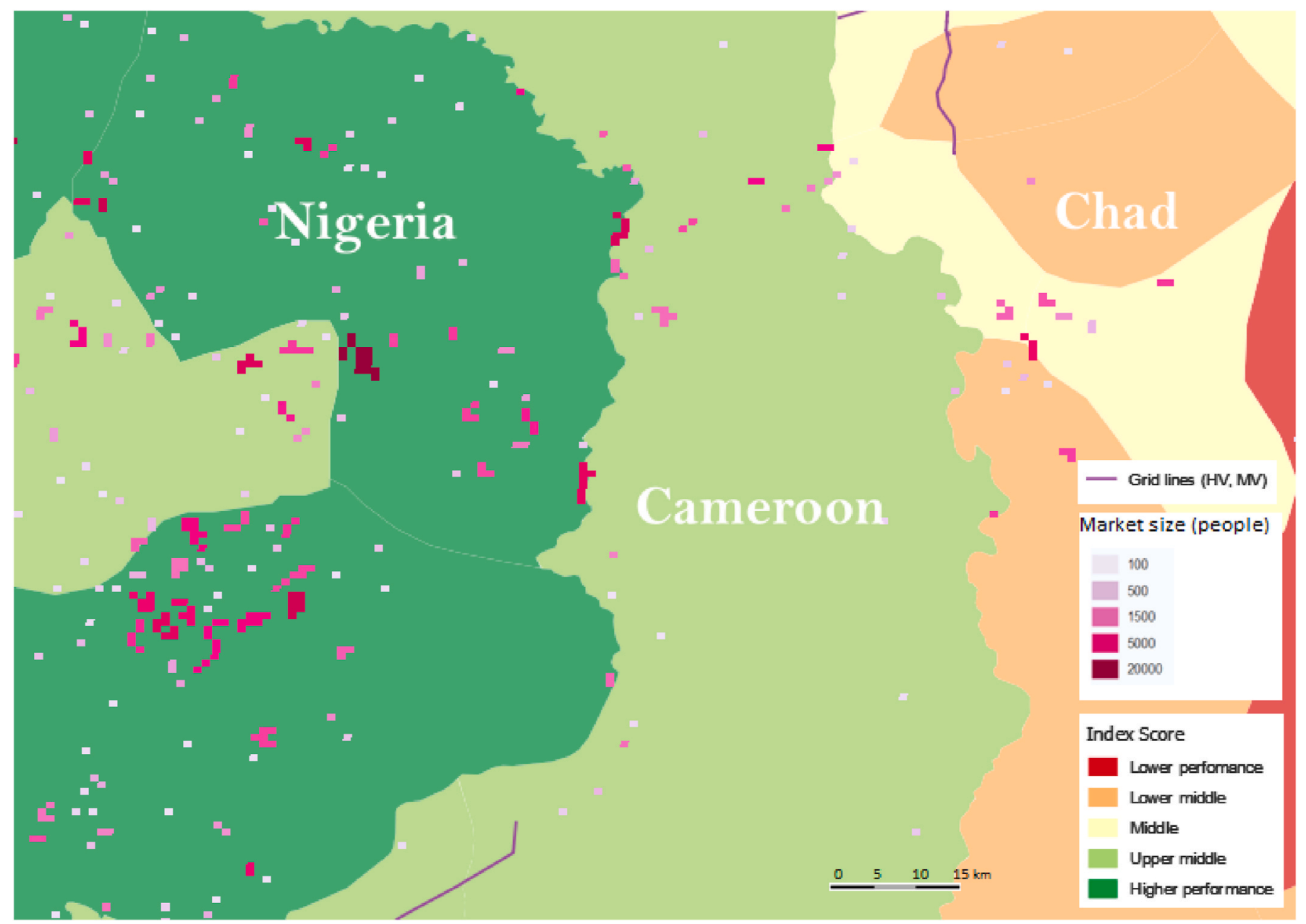

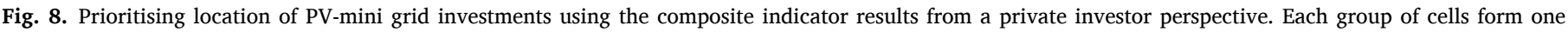

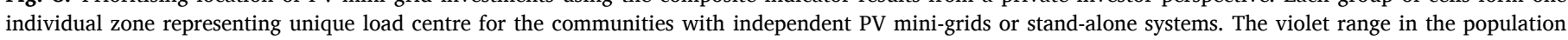
pixels depicts the market size per system (total potential new costumers).

measures decentralised energy options, the market size in each country is meaningful to establish the ranking.

Fig. 4 also breaks down how countries score on each of the dimensions. Low-ranking countries on the PV-DEI Index tend to score poorly on financial considerations, despite obtaining relatively high scores in the environmental and social dimensions. For example, Madagascar ranked third in the environmental dimension but was ranked in 32nd position in the overall index. The importance of financial considerations for determining the location of solar-PV investments is attested to by the current global location of solar-PV predominantly in the northern rather than the sunnier southern hemisphere (where irradiation is higher but access to affordable, secured capital is lower) [65]. It also reflects the weighting system illustrated here, which came from a private finance perspective. Our study links PV-DEI investment to variability in financing conditions for the first time at the country level across in SSA.

The differences between countries in the Western African region emphasise the importance of including indicators that go beyond the availability of resources. Senegal achieved greater scores in the political and social dimensions that its neighbours, Sierra Leone and the Ivory Coast. Thus, despite their proximity, these countries are ranked very differently in the index, better reflecting the broad range of considerations in locating a PV-DEI investment.

The sensitivity analysis illustrates whether the scores (and the associated inferences) are robust with changes in stakeholder perspectives $[66,67]$. The weightings from the stakeholders that were engaged can be found in the SI_indicators_raw_data. Fig. 5 depicts how the index scores for the countries changed in relation to three different expert assumptions. For instance, Ethiopia keeps ranking the most favourable country regardless of different stakeholder approach, on the contrary, Chad appears to be very sensitive to the weighting of the stakeholders, changing the ranking from an $18^{\text {th }}$ position from a private perspective to second one when environmental and social aspects are considered a priority for investments (civil society and international donor perspectives).

The purpose of the composite indicator is to allow for multiple perspectives, and these can easily be visualised by altering the weights placed on different components of the indicator (including environmental, political and social, not just financial). In the decision processes of international donor organisations there often exists a multidimensional set of requirements that go beyond one factor, thus the composite indicator represents a new method for allowing their preferences to be expressed, as the weighting system can be tailored appropriately.

As private investments and thus financial incentives dominate the current discourse the weightings system presented here reflects this, but in including other criteria the paper represents a step away from maintaining the sole dominance of financial considerations. The earth observation derived data embedded within the index, combined with the LCOE, can also capture sub-national differences within countries to determine whether there was a sub-region of a country more amenable to decentralised options (Fig. 6). This allows potential areas for 


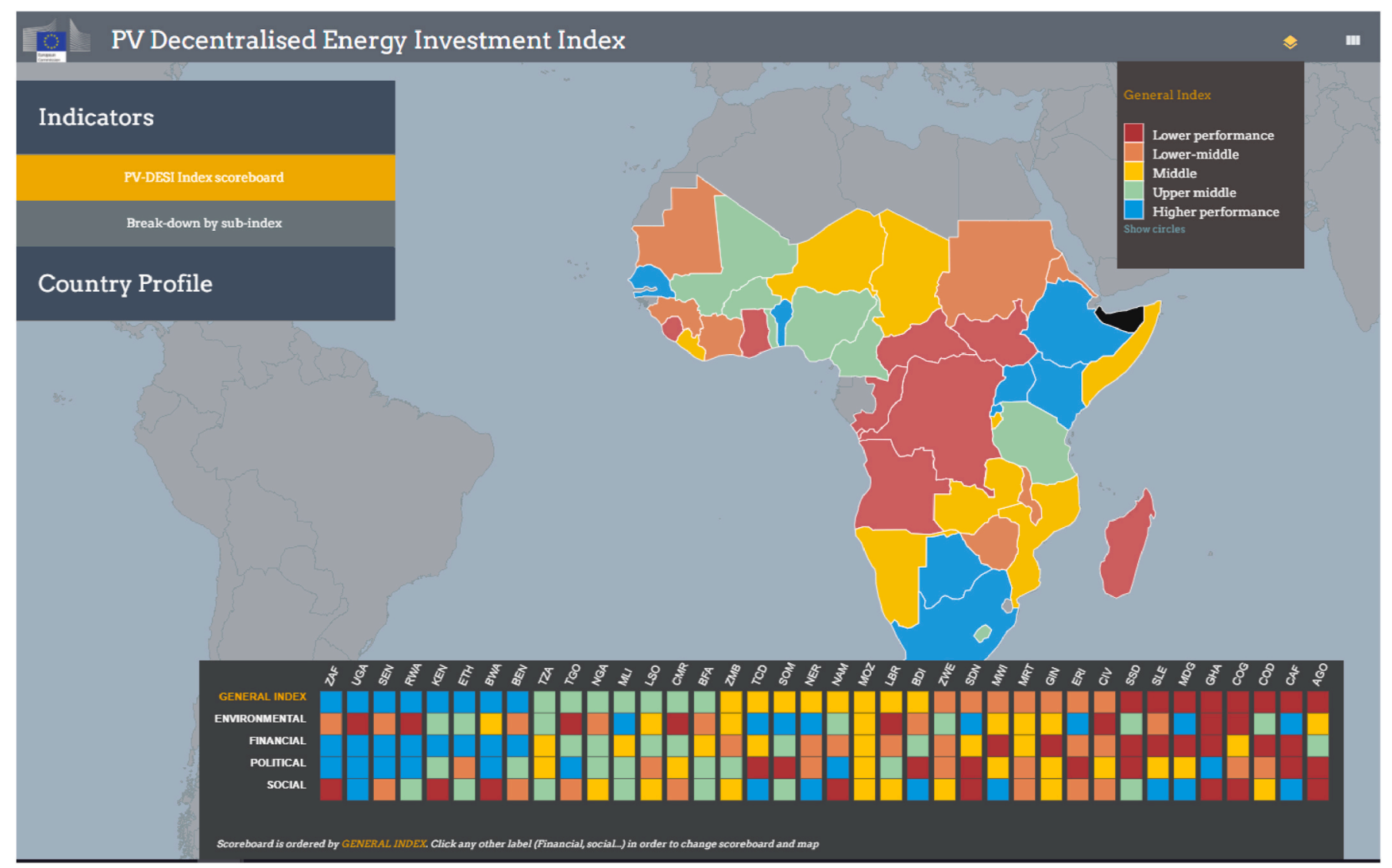

Fig. 9. The PV-DEI open source and open-access analytical web-tool.

investment to be identified at considerable spatial detail.

The PV-DEI index ranks the attractiveness of countries for investments in decentralised PV and enables the impacts of potential investments to be more explicitly quantified. The PV-DEI framework considers potential size of the PV market investments (number of potential new beneficiaries in non-electrified areas), the associated total investment costs (including poverty index in the level of consumption) and the avoided emissions (see SI).

Using these factors, Fig. 7 distinguishes the high and low performing countries for attracting decentralised PV technologies, and the potential for mitigating climate change. For instance, in the case of the 3-top countries, the market size ranges from 64 million people for Ethiopia to 4 million people for South Africa (see Fig. 7). Although the magnitude of the market size is subject to considerable uncertainty, the range of costs among each country remains relatively well established across a range of model specifications. In terms of allocated market size Ethiopia, Nigeria and Congo dominate all the other nations, and on top of this the three countries have a mid-range average cost of production, making them attractive for investment when considering these three indicators. However, the composite indicator results show that Congo has the lowest score in the PV-DEI index, which would make the investment less attractive. At the other end of the scale, South Africa has a high index score but would accrue a significantly smaller share of the market and has a higher LCOE. These examples illustrate the value of accounting for the various factors within a unified framework that additionally allows for stakeholders to view individual indicator data.

\subsection{Prioritising location of PV-mini grid investments at regional-level}

As a final example, Fig. 8 shows how the PV-DEI index and accompanying high resolution spatial data might be used for locating a specific new solar-PV investment project. The most favourable sub-regions for
PV decentralised investments, according to the PV-DEI index, are coloured dark green, while coloured pixels show potential market size. Each group of cells (unique zone) represents a unique load centre for the communities with independent PV mini-grids or stand-alone systems. This approach can be used to calculate the total population covered by each system (market size) and the total amount of cumulative investment required over a 20-year lifetime, per system (see section material and methods).

\section{Discussion}

The PV-DEI composite indicator has a significant potential to support decision making and be used by multiple actors involved in energy access in Sub-Saharan Africa - namely, rural electrification agencies, intergovernmental organizations, governments, international donor, NGOs, and mini-grid developers. Many composite indicators already exist in somewhat-related topics, such as the UNDP's Human Development Index [25], the World Bank's Ease of Doing Business index [26], the Global innovation index [27], the OECD Green Growth Indicators [68] and the African Green Growth Index [69], the Renewable Energy Country Attractiveness Index (RECAI) ranks the top 40 markets in the world on the attractiveness of their renewable energy investment and deployment opportunities. Recently, the Sustainable Development Goals (SDGs) Index was launched, a composite measure of progress covering 85 indicators across all 17 SDGs [28-30]. However, the PV-DEI index is the first to directly address investments in sustainable energy development and rural electricity access.

The analytical tools presented here have the novel capability of being able to identify countries' strengths and weaknesses, thereby pointing to possible improvements that may be made within an individual country to improve its attractiveness for decentralised solar-PV investment. These improvements could then increase stakeholder confidence in the 
investments of PV decentralised options in non-electrified SSA areas. The index encapsulates the multiple factors considered by stakeholders when making decentralised solar-PV investment decisions, and are included within the PV-DEI index using a combination of Earth Observation data and country level scores on various social and political dimensions in an original, objective and spatially distinct way. This allows users of the Index to investigate the relationships between disparate variables from different research domains.

The PV-DEI index clearly differentiates between SSA countries, thus preventing problematic generalisations across the SSA region as a whole, which can impede viable investments. In particular, the PV-DEI index results highlight the need for the lowest ranking countries to facilitate the involvement of development finance institutions and other risk mitigation measures to improve the financial conditions for investments, even for those countries with large solar resources and low production costs. The index will be tracked over time to assess the progression of attractiveness of all SSA countries in terms of decentralised options.

Composite indicators, like any model, involve a number of assumptions in their construction. In particular, the relative weighting of indicators and dimensions within the concept will vary depending on the stakeholders and the application. For this reason, and to provide full exploration of the underlying data the upcoming open source PV-DEI web-tool (Fig. 9) will enable its users to visualise the index results in an interactive way, to suit their needs and to create their own tailored PV-investment index. This is achieved by allowing users analysing data on specific individual indicators or selected countries.

Users can tailor the weights assigned to the different indicators to match their specific requirements and to express their criteria for investment in more nuanced ways. For example, a philanthropic organisation may use the tool to focus specifically on the social pillar, using the $\mathrm{PV}$-DEI index to find regions where investment in electricity generation may have the greatest social benefits. Other users may focus on specific risk mitigation potential of reducing the energy service gap between urban a rural population.

Finally, the composite indicator offers an access point to the underlying indicator data for relevant stakeholders (rural electrification agencies, intergovernmental organizations, governments, international donor, NGOs, mini-grid developers, etc.).

\section{Conclusions}

The results presented here from the private sector approach show that the three highest-scoring countries (Ethiopia, Kenya and South Africa) are also among the top-ranked countries in financial aspects. However, these three top-scoring countries show lower scores from the social dimension (ranking $24^{\text {th, }} 31^{\text {st }}$ and $38^{\text {th }}$ position), indicating that Chad, Niger and Central African Republic are likely to significantly improve various social outcomes by investing in decentralised PV (i.e. maximising job creation and increase in quality of education and health conditions per Euro invested). The PV-DEI framework estimates the potential size of the PV decentralised market investments, the associated total investment costs and the avoided emissions. For instance, in the case of the top 3 countries, the market size ranges from 64 million people for Ethiopia to 4 million people for South Africa, while the total investment costs (NPV) accounting for 20 years ranges from EUR 890 to 525 million, respectively. Although the magnitude of the market size is subject to considerable uncertainty, the range of costs among each country remains relatively well-established across a range of model specifications. The LCOE values per country (without including softcosts) ranges from 0.18 to $0.27 \mathrm{EUR} / \mathrm{kWh}$, the LCOE is calculated considering only the areas covered by decentralised options.

Up to now, most Electrification Master Plans in Sub-Saharan Africa were skewed toward centralised options, as they did not include such geographic resolution making it impossible to effectively consider distributed generation options. An important indication for the lower performing countries is that the PV-DEI index highlights the importance of developing the necessary policy and regulatory framework to catalyse investments in rural areas.

The geospatial analysis at high-spatial resolution developed in this study combined with country-level indicator data allows to effectively identify locations for new solar-PV investment projects, taking into account not only the location specific production costs but broader social, political and environmental factors. This is to be implemented interactively in the PV-DEI interactive tool linked to this study.

The spatial data are collected from open data sources that can be found in the referenced papers, the economic assessment uses the NPV and LCOE standard methodology, and the statistical methods used are described in the COIN tool [36]. The COIN tool especially encourages participatory uses and provides options even to factor in user preferences and weighting in the analysis. Moreover, it is important to remark that to facilitate the reproducibility by other studies and avoid the "black box" effect the source files of the index calculation and the raw data are included in this study (SI).

A few limitations should be mentioned. First, given the rapid changes occurring in some countries, some scores may be sensitive to the time when the data was collected. The PV-DEI index currently only covers one specific point in time, although future work will extend the web-tool to measure the evolution of the index over time. Future research could also investigate normalising PV-DEI index scores within regions of SSA, to calculate the optimal areas for decentralised PV within these. This would prevent the systematic exclusion of central African countries, which scored poorly in relation to SSA as a whole. In further developments, the index will include other decentralised options such as small wind turbines [49] and mini-hydro technologies [10,70,71]. Finally, the PV-DEI index methodology gives a strong basis, in the long-term, to be extended to the integration of PV to the existing power systems.

\section{Data availability}

The datasets generated during this study are included in the SI and available at https://data.jrc.ec.europa.eu/, an open-source online data repository hosted at the Joint REsearch Centre-European Commission.

\section{Credit author statement}

Moner-Girona, M, Conceptualization, Methodology, Investigation, Visualization, Writing, Review \& Editing. Bender, A, Conceptualization, Methodology, Validation, Investigation, Writing, Review \& Editing. Becker, W, Methodology, Investigation, Writing, Review \& Editing. Bódis, K, Data processing, Geospatial modelling and analysis, Visualization. Szabó, S, Investigation, Writing, Review \& Editing. Kararach, A. G, Writing, Review \& Editing. Anadon, L. D, Conceptualization, Writing, Review \& Editing.

\section{Disclaimer}

The views expressed are purely those of the authors and may not in any circumstances be regarded as stating an official position of the European Commission.

\section{Declaration of competing interest}

The authors declare that they have no known competing financial interests or personal relationships that could have appeared to influence the work reported in this paper.

\section{Acknowledgements}

The authors would like to thank Nigel Taylor (Joint Research Centre, European Commission) for providing valuable insights and supporting 
the follow-up interactive tool of this study. We would like to acknowledge Pere Roca Ristol (Joint Research Centre - European Commission) for the development of the PV-DEI web tool. The authors would like to thank the department for International Partnerships (DG INTPA) F.1 unit- European Commission for providing valuable insights and supporting the development of the interactive tool of this study.

\section{Appendix A. Supplementary data}

Supplementary data related to this article can be found at https://do i. org/10.1016/j.rser.2021.111282.

\section{References}

[1] World Bank. Sustainable energy for all (SE4ALL ) database from the SE4ALL global tracking framework. 2018. https://data.worldbank.org/.

[2] International Energy Agency. Africa energy outlook. 2019. Paris, France.

[3] The World Bank Group. From billions to trillions: transforming development finance. Washington D.C.: Development Committee Paper; 2015. Bank, African Development Bank, the Asian Development Development, the European Bank for Reconstruction and Bank, the European Investment The Bank Development InterAmerican Fund Monetary, the International.

[4] Sustainable Energy forAll (SEforALL) and the Climate Policy Initiative (CPI). Energy finance: understanding the landscape 2019. 2019. Vienna, Austria.

[5] Casillas CE, Kammen DM. The energy-poverty-climate nexus. Renew Energy 2010; 330:1181-2.

[6] Bazilian M, Nussbaumer P, Rogner HH, Brew-Hammond A, Foster V, Pachauri S, et al. Energy access scenarios to 2030 for the power sector in sub-Saharan Africa. Util Pol 2012;20:1-16. https://doi.org/10.1016/j.jup.2011.11.002.

[7] Duan L, Moreno-Cruz J, Caldeira K. Balancing climate and development goals. Environ Res Lett 2019. https://doi.org/10.1088/1748-9326/abbe46.

[8] Mutezo G, Mulopo J. A review of Africa's transition from fossil fuels to renewable energy using circular economy principles. Renew Sustain Energy Rev 2021. https://doi.org/10.1016/j.rser.2020.110609.

[9] International Energy Agency. Africa Energy Outlook. A focus on the energy prospects in sub-Saharan Africa. 2014. https://www.iea.org/publications/freepu blications/publication/africa-energy-outlook.html.

[10] Szabó S, Bódis K, Huld T, Moner-Girona M. Energy solutions in rural Africa: mapping electrification costs of distributed solar and diesel generation versus grid extension. Environ Res Lett 2011;6:034002. https://doi.org/10.1088/1748-9326 6/3/034002.

[11] Rosnes O, Vennemo H. Powering Up: costing power infrastructure spending needs in Sub-Saharan Africa, vol. 5; 2009. Washington, DC.

[12] Van de Walle N. Africa's infrastructure: a time for transformation. Foreign Aff 2010;89:154.

[13] ESMAP. SE4ALL. Beyond connections. Energy access redefined. Washington, D.C. the international bank for reconstruction and development. The World Bank; 2015

[14] Weiss DJ, Nelson A, Gibson HS, Temperley W, Peedell S, Lieber A, et al. A global map of travel time to cities to assess inequalities in accessibility in 2015. Nature 2018. https://doi.org/10.1038/nature25181.

[15] Eberhard A, Rosnes O, Shkaratan M, Vennemo H. Africa's power infrastructure: investment, integration, efficiency. Washington, DC: The World Bank; 2011.

[16] The World Bank. World development indicators [database]. 2020.

[17] World Resources Institute. Linking electricity access and development outcomes in Africa: a framework for action. 2020.

[18] ESMAP, The World Bank. A retrospective analysis of the role of isolated and mini grids in power system development. Washington DC: The International Bank for Reconstruction and Development/The World Bank; 2017. https://doi.org/ $10.1596 / 29023$.

[19] Bloomberg New Energy Finance. Kenya - climatescope 2018. http://global-climatescope.org/en/country/kenya/\#/details. [Accessed 27 November 2015].

[20] Steffen B, Schmidt TS. A quantitative analysis of 10 multilateral development banks' investment in conventional and renewable power-generation technologies from 2006 to 2015. Nat Energy 2019. https://doi.org/10.1038/s41560-018-02803.

[21] Giamporcaro S. The African investing for impact barometer 2016. Cape Town, South Africa: Bertha Centre, University of Cape Town Graduate School of Business 2017.

[22] Schwerhoff G, Sy M. Financing renewable energy in Africa - key challenge of the sustainable development goals. Renew Sustain Energy Rev 2017;75:393-401. https://doi.org/10.1016/j.rser.2016.11.004.

[23] Eberhard A, Gratwick K, Morello E, Antmann P. Accelerating investments in power in sub-Saharan Africa. Nat Energy 2017. https://doi.org/10.1038/nenergy.2017.5.

[24] Fonta WM, Ayuk ET, van Huysen T. Africa and the Green Climate Fund: current challenges and future opportunities. Clim Pol 2018. https://doi.org/10.1080/ 14693062.2018.1459447.

[25] UNDP. Human Development Report 2019. Beyond income, beyond averages, beyond today. Inequalities in human development in the 21st century. New York, US: UNDP; 2019.

[26] World Bank. Doing business 2020. 2020. https://doi.org/10.1596/978-1-46481440-2. Washington, DC
[27] Cornell University. INSEAD, world intellectual property organization. Global innovation index 2019. Creating healthy lives. The future of medical innovation. Ithaca, Fontainebleau, and Geneva: World Intellectual Property Organization (WIPO); 2019.

[28] Schmidt-Traub G, Kroll C, Teksoz K, Durand-Delacre D, Sachs JD. National baselines for the sustainable development goals assessed in the SDG index and dashboards. Nat Geosci 2017. https://doi.org/10.1038/NGEO2985.

[29] Papadimitriou E, Neves AR, Becker W. JRC statistical audit of the sustainable development goals index and dashboards. Luxembourg: Publications Office of the European Union; 2019. https://doi.org/10.2760/723763.

[30] United Nations. Sustainable development goals report 2019. 2019. New York, US.

[31] Mainali B, Pachauri S, Rao ND, Silveira S. Assessing rural energy sustainability in developing countries. Energy Sustain Dev 2014. https://doi.org/10.1016/j. esd.2014.01.008.

[32] Tampakis S, Tsantopoulos G, Arabatzis G, Rerras I. Citizens' views on various forms of energy and their contribution to the environment. Renew Sustain Energy Rev 2013. https://doi.org/10.1016/j.rser.2012.12.027.

[33] Nardo M, Saisana M, Saltelli A, Tarantola S, Hoffman A, Giovannini E. Handbook on constructing composite indicators. 2005. https://doi.org/10.1787/ 533411815016 .

[34] Wang JJ, Jing YY, Zhang CF, Zhao JH. Review on multi-criteria decision analysis aid in sustainable energy decision-making. Renew Sustain Energy Rev 2009. https://doi.org/10.1016/j.rser.2009.06.021.

[35] Joint Research Centre-European Commission. EU Survey: expert consultation on PV mini-grids in Africa. https://ec.europa.eu/eusurvey/runner/PV_mini-grid_Afr ica. [Accessed 9 September 2019].

[36] Becker W, Benavente D, Dominguez Torreiro M, Moura C, Neves A, Saisana M, et al. COIN tool user guide. EUR 29899 EN, Publications Office of the European Union; 2019. https://doi.org/10.2760/523877.

[37] Doll CNH, Pachauri S. Estimating rural populations without access to electricity in developing countries through night-time light satellite imagery. Energy Pol 2010. https://doi.org/10.1016/j.enpol.2010.05.014.

[38] Szabó S, Moner-Girona M, Kougias I, Bailis R, Bódis K. Identification of advantageous electricity generation options in sub-Saharan Africa integrating existing resources. Nat Energy 2016;1. https://doi.org/10.1038/ nenergy. 2016.140.

[39] Szabó S, Pinedo Pascua I, Puig D, Moner-Girona M, Negre M, Huld T, et al. Mapping of affordability levels for photovoltaic-based electricity generation in the solar belt of sub-Saharan Africa, East Asia and South Asia. Nat Sci Reports 2021. https://doi.org/10.1038/s41598-021-82638-x. 11.

[40] Falchetta G, Pachauri S, Parkinson S, Byers E. A high-resolution gridded dataset to assess electrification in sub-Saharan Africa. Sci Data 2019. https://doi.org/ 10.1038/s41597-019-0122-6.

[41] Joint Research Centre-European Commission. Competence centre on composite indicators and Scoreboards. https://composite-indicators.jrc.ec.europa.eu/. [Accessed 21 January 2020].

[42] International Monetary Fund. International financial statistics and data. https:// www.imf.org/en/Data; 2019.

[43] Shah AD, Bartlett JW, Carpenter J, Nicholas O, Hemingway H. Comparison of random forest and parametric imputation models for imputing missing data using MICE: a caliber study. Am J Epidemiol 2014.

[44] The World Bank. Doing business 2019: training and reform. 2019. https://doi.org/ 10.1596/978-1-4648-1326-9. Washington DC, US.

[45] Klein SJW, Whalley S. Comparing the sustainability of U.S. electricity options through multi-criteria decision analysis. Energy Pol 2015. https://doi.org/ 10.1016/j.enpol.2015.01.007.

[46] Nock D, Baker E. Holistic multi-criteria decision analysis evaluation of sustainable electric generation portfolios: new England case study. Appl Energy 2019. https:// doi.org/10.1016/j.apenergy.2019.03.019.

[47] Moner-Girona M, Bódis K, Korgo B, Huld T, Kougias I, Pinedo-Pascua I, et al. Mapping the least-cost option for rural electrification in Burkina Faso. 2017.

[48] Huld T, Moner-Girona M, Kriston A. Geospatial analysis of photovoltaic mini-grid system performance. Energies 2017;10:218. https://doi.org/10.3390/ en10020218.

[49] Moner-Girona M, Bódis K, Morrissey J, Kougias I, Hankins M, Huld T, et al. Decentralized rural electrification in Kenya: speeding up universal energy access. Energy Sustain Dev 2019. https://doi.org/10.1016/j.esd.2019.07.009.

[50] European commission joint research centre (JRC), columbia university center for international earch science information Network (CIESIN). GHS population grid, derived from GPW4, multitemporal $(1975,1990,2000,2015) 2015$.

[51] European Commission- Joint Research Centre (JRC). Photovoltaic geographical information system (PVGIS). https://ec.europa.eu/jrc/en/pvgis. [Accessed 1 September 2019].

[52] EU PV Technology Platform. PV LCOE in europe 2014-30, vol. 1. Brussels, Belgium: EU PV Platform; 2015. https://doi.org/10.1017/CBO9781107415324.004.

[53] Moner-Girona M, Solano-Peralta M, Lazopoulou M, Ackom E, Vallve X, Szabó S. Electrification of Africa through PV/hybrid mini-grids: reducing the gap between current business models and on-site experience. 2018.

[54] Paresi M, Melchiorri M, Siragusa A, Kemper T. Atlas of the human planet. Mapping human presence on earth with the global human settlement layer. Luxembourg: Publications Office of the European Union; 2017. https://doi.org/10.2788/ 889483.

[55] European Commission Joint Research Centre (JRC). Global Human Settlement Layer (2019). Ghs_pop2019 @ghslJrcEcEuropaEu n.d. https://ghsl.jrc.ec.europa. eu/ghs_pop2019.php (accessed July 7, 2019). 
[56] Arderne C, Zorn C, Nicolas C, Koks EE. Predictive mapping of the global power system using open data. Sci Data 2020. https://doi.org/10.1038/s41597-0190347-4.

[57] ECREEE. ECOWREX. ECOWAS observatory for renewable energy and energy efficiency. http://www.ecowrex.org/. [Accessed 23 February 2019].

[58] Moner-Girona M, Bódis K, Huld T, Kougias I, Szabó S. Universal access to electricity in Burkina Faso: scaling-up renewable energy technologies. Environ Res Lett 2016;11. https://doi.org/10.1088/1748-9326/11/8/084010.

[59] Aly A, Moner-Girona M, Szabó S, Pedersen AB, Jensen SS. Barriers to large-scale solar power in Tanzania. Energy Sustain Dev 2019;48:43-58. https://doi.org/ 10.1016/j.esd.2018.10.009.

[60] Moner-Girona M, Ghanadan R, Solano-Peralta M, Kougias I, Bódis K, Huld T, et al Adaptation of Feed-in Tariff for remote mini-grids: Tanzania as an illustrative case. Renew Sustain Energy Rev 2016;53:306-18. https://doi.org/10.1016/j. rser.2015.08.055.

[61] NASA Earth Observatory. Earth at Night 2019. https://earthobservatory.nasa. gov/(accessed May 7, 2019).

[62] Andrade-Pacheco R, Savory DJ, Midekisa A, Gething PW, Sturrock HJW, Bennett A Household electricity access in Africa (2000-2013): closing information gaps with model-based geostatistics. PloS One 2019;14:1-14. https://doi.org/10.1371/ journal.pone.0214635.

[63] Data: Electricity Africa n.d. https://github.com/ric70x7/ElectricityAfrica (accessed February 9, 2019).

[64] IEA, IRENA, UNSD, World Bank, WHO. Tracking SDG 7: the energy progress report. Washington DC, US: World Bank Publications; 2020.

[65] Ondraczek J, Komendantova N, Patt A. WACC the dog: the effect of financing costs on the levelized cost of solar PV power. Renew Energy 2015;75:888-98.
[66] Morgan MG. Use (and abuse) of expert elicitation in support of decision making for public policy. Proc Natl Acad Sci U S A 2014. https://doi.org/10.1073/ pnas.1319946111.

[67] Saisana M, D'Hombres B, Saltelli A. Rickety numbers: volatility of university rankings and policy implications. Res Pol 2011. https://doi.org/10.1016/j. respol.2010.09.003.

[68] OECD. Green growth indicators 2017. Paris, France: OECD; 2017. https://doi.org/ 10.1787/9789264268586-en.

[69] Kararach G, Nhamo G, Mubila M, Nhamo S, Nhemachena C, Babu S. Reflections on the Green Growth Index for developing countries: a focus of selected African countries. Dev Pol Rev 2018. https://doi.org/10.1111/dpr.12265.

[70] Szabó S, Bódis K, Huld T, Moner-Girona M. Sustainable energy planning: leapfrogging the energy poverty gap in Africa. Renew Sustain Energy Rev 2013;28: 500-9. https://doi.org/10.1016/j.rser.2013.08.044.

[71] Szabó S, Moner-Girona M, Kougias I, Bailis R, Bódis K. Identification of advantageous electricity generation options in sub-Saharan Africa integrating existing resources. Nat Energy 2016;1:16140. https://doi.org/10.1038/ nenergy.2016.140.

[72] García-Gusano D, Espegren K, Lind A, Kirkengen M. The role of the discount rates in energy systems optimisation models. Renew Sustain Energy Rev 2016. https:// doi.org/10.1016/j.rser.2015.12.359.

[73] ENTSO-E. Guideline for cost benefit analysis of grid development projects. Brussels, Belgium: European Network of Transmission System Operators (ENTSO); 2020.

[74] Kougias I, Szabó S, Nikitas A, Theodossiou N. Sustainable energy modelling of noninterconnected Mediterranean islands. Renew Energy 2019. https://doi.org/ 10.1016/j.renene.2018.10.090. 